\title{
Evaluation of Environmental Controls at a Homeless Shelter Associated with a Tuberculosis Outbreak - Texas
}

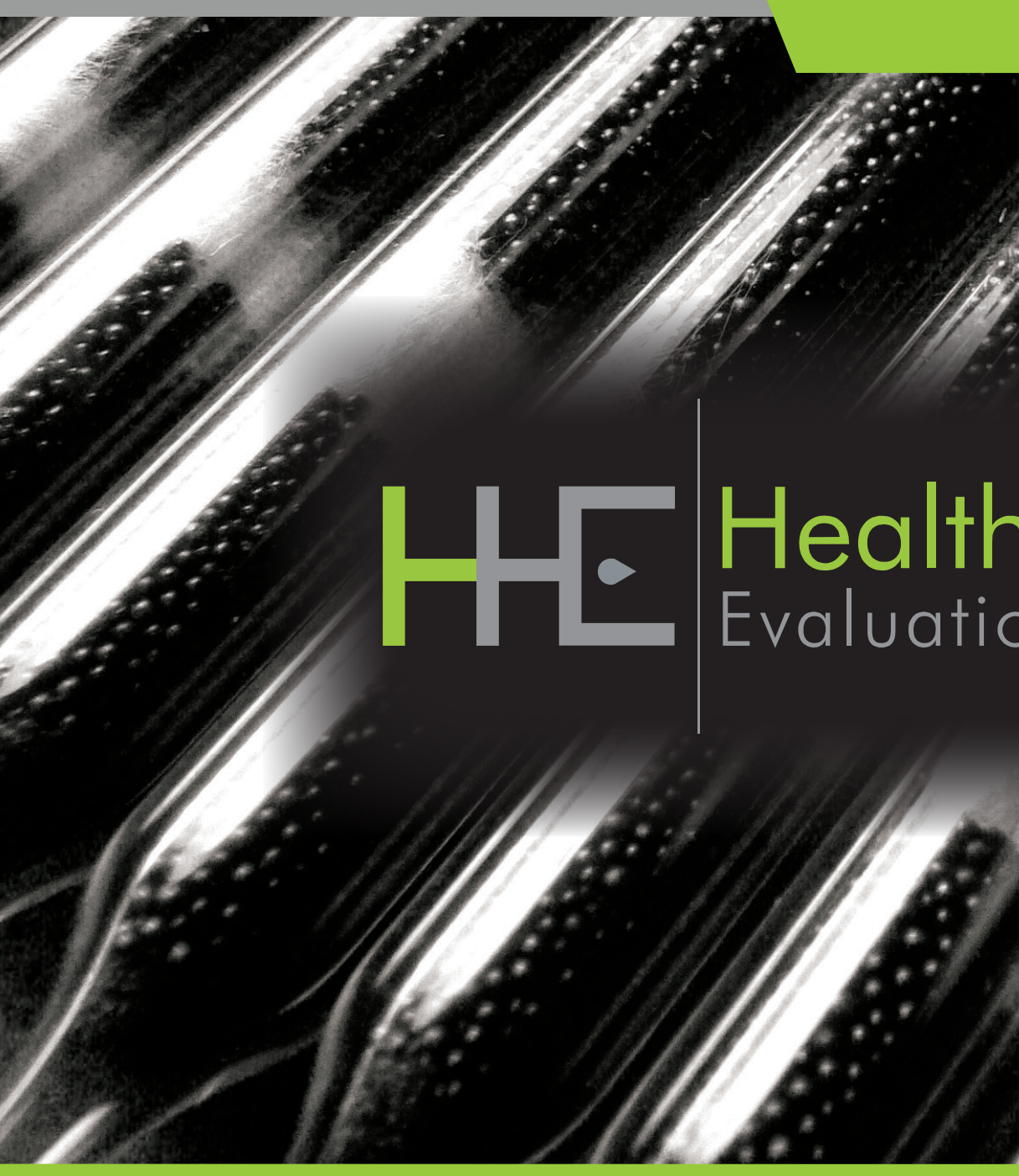

Report No. 2013-0145-3209 May 2014
Stephen B. Martin, Jr., MS, PE R. Brent Lawrence, MS, GSP Kenneth R. Mead, PhD, PE 


\section{Contents}

Highlights i

Abbreviations ...................................................................................... iv

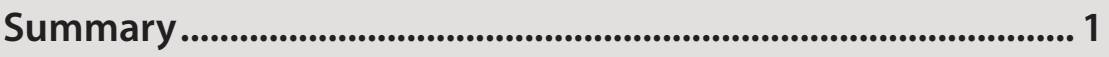

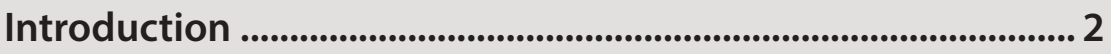

Background ............................................................................................... 3

Assessment ................................................................................................ 4

Results \& Discussion .................................................................. 5

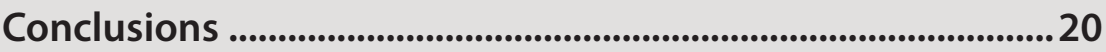

Recommendations ................................................................ 21

Outline of Future NIOSH Involvement.................................... 25

References.............................................................................2 27

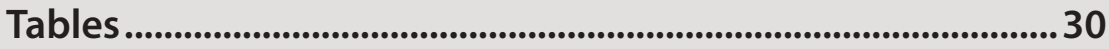

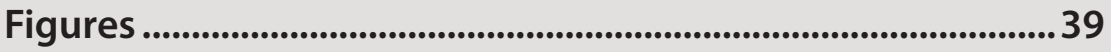

Acknowledgements .................................................................................4 42

The employer is required to post a copy of this report for 30 days at or near the workplace(s) of affected employees. The employer must take steps to ensure that the posted report is not altered, defaced, or covered by other material.

The cover photo is a close-up image of sorbent tubes, which are used by the HHE Program to measure airborne exposures. This photo is an artistic representation that may not be related to this Health Hazard Evaluation. 


\section{Highlights of this Evaluation}

The National Institute for Occupational Safety and Health (NIOSH) received a technical assistance request from the manager of a large homeless shelter in Dallas, Texas. The request asked NIOSH to assess the heating, ventilation, and air-conditioning systems and make recommendations to improve overall environmental controls, as the shelter had epidemiological links to an ongoing tuberculosis (TB) outbreak.

\section{What NIOSH Did}

- Visited the shelter on June 5-7, 2013.

- Met with representatives from the Dallas County Department of Health and Human Services to discuss the ongoing TB outbreak, and to outline our goals and objectives for our site visits.

- Recorded the physical sizes of occupied spaces.

- Measured ventilation air flow into/from occupied spaces.

- Collected information on all air-handling units.

\section{What NIOSH Found}

- The shelter was working closely with the Dallas County Department of Health and Human Services on TB outbreak response efforts, including implementation of more robust administrative controls.

- Air-handling units were well maintained, fitted with proper filter configurations, and in good working order.

- Little outdoor air was being supplied to occupied spaces by building mechanical systems under certain occupancy and environmental conditions.

- There was no clearly defined area to separate guests suspected of having tuberculosis or other airborne infectious disease from the general guest population.

- Some medical clinic examination rooms and most bathrooms and shower rooms at the facility were incorrectly operating under positive pressure compared to adjacent spaces.

- A written respiratory protection plan did not exist.

\section{What the Shelter Can Do}

- Continue to work in close conjunction with the Dallas County Department of Health and Human Services to improve overall administrative controls to help ensure rapid identification of guests suspected to have tuberculosis.

- Develop a comprehensive infection control plan with input from the Dallas County Department of Health and Human Services. 
- Modify the sequence of operations for existing air-handling units and/or augment shelter ventilation systems to provide adequate outdoor air to all occupied spaces under all occupancy and environmental conditions.

- For each air-handling unit, install the highest efficiency air filter possible that is consistent with the proper operation of the air-handling unit.

- Create an enclosed, ventilated space in the pavilion sleeping area for use as a respiratory separation area, when necessary.

- Adjust or modify ventilation systems to properly maintain all medical examination rooms under negative pressure relative to the adjacent spaces.

- Install a properly designed upper-air ultraviolet germicidal irradiation system in the pavilion sleeping area.

- Repair or replace bathroom and shower room exhaust fans so those spaces are maintained under negative pressure relative to adjacent spaces.

- Develop and implement a written respiratory protection program that meets the requirements of the Occupational Safety and Health Administration's respiratory protection standard 29 Code of Federal Regulations 1910.134.

- Develop and implement a written operation and maintenance plan for shelter heating, ventilation, and air-conditioning systems, to include a filter replacement schedule. 
This page left intentionally blank 


\section{Abbreviations}

\begin{tabular}{|c|c|}
\hline$\mu \mathrm{m}$ & Micrometer \\
\hline AHU(s) & Air-handling unit(s) \\
\hline ACGIH & American Conference of Governmental Industrial Hygienists \\
\hline $\mathrm{ACH}$ & Air changes per hour \\
\hline AII & Airborne infection isolation \\
\hline ANSI $^{\oplus}$ & American National Standards Institute \\
\hline ASHRAE $^{\oplus}$ & American Society of Heating, Refrigerating and Air-Conditioning Engineers \\
\hline CDC & Centers for Disease Control and Prevention \\
\hline $\mathrm{cfm}$ & Cubic feet per minute \\
\hline CFR & Code of Federal Regulations \\
\hline DCHHS & Dallas County Department of Health and Human Services \\
\hline DRDS & Division of Respiratory Disease Studies \\
\hline DTBE & Division of Tuberculosis Elimination \\
\hline FGI & Facility Guidelines Institute \\
\hline HEPA & High-efficiency particulate air \\
\hline HVAC & Heating, ventilation, and air-conditioning \\
\hline ICP & Infection control plan \\
\hline$\mu \mathrm{W} / \mathrm{cm} 2$ & Microwatts per square centimeter \\
\hline $\mathrm{mJ} / \mathrm{cm} 2$ & Millijoules per square centimeter \\
\hline MERV & Minimum efficiency reporting value \\
\hline $\mathrm{nm}$ & Nanometer \\
\hline NCHHSTP & National Center for HIV/AIDS, Viral Hepatitis, STD, and TB Prevention \\
\hline NIOSH & National Institute for Occupational Safety and Health \\
\hline O\&M & Operation and maintenance \\
\hline OSHA & Occupational Safety and Health Administration \\
\hline REL & Recommended Exposure Limit \\
\hline $\mathrm{RH}$ & Relative humidity \\
\hline $\mathrm{TB}$ & Tuberculosis \\
\hline UV & Ultraviolet \\
\hline UVGI & Ultraviolet germicidal irradiation \\
\hline
\end{tabular}




\section{Summary}

On May 22, 2013, the National Institute for Occupational Safety and Health (NIOSH) received a request for technical assistance from the shelter manager at a large homeless shelter in Dallas, Texas, linked to an ongoing tuberculosis outbreak. The request asked $\mathrm{NIOSH}$ to assess the heating, ventilation, and air-conditioning (HVAC) systems and make recommendations to improve overall environmental controls at the shelter.

During an on-site evaluation of the homeless shelter in June 2013, we collected physical and ventilation measurements in all key areas of the facility. We focused on areas where shelter guests typically congregate or spend significant amounts of time. We recorded the make and model number of all air-handling units (AHUs) providing air to the facility, and visually inspected the units. When possible, we measured the air flow rate through supply diffusers and return grilles.

The AHUs in place were state-of-the-art and were controlled by a modern building automation system. The ventilation systems were well maintained and functional during our visit, and all AHUs were equipped with proper filter configurations. Despite their excellent condition and maintenance, certain aspects of the ventilation systems' operation could potentially contribute to

\section{$\mathrm{NIOSH}$ investigators} conducted an assessment of environmental controls at a large Dallas, Texas, homeless shelter linked to an ongoing tuberculosis outbreak. The investigation revealed problems with the existing environmental controls, along with needed improvements in administrative controls and respiratory protection. Detailed recommendations are provided in this report to improve the shelter environment and reduce the likelihood of disease transmission. airborne disease transmission among shelter guests. During our visit, it appeared the AHUs were not providing adequate outdoor air to the occupied spaces under certain occupancy and environmental conditions, as is required by the Dallas Mechanical Code and ASHRAE standards. In addition to alleviating odors and maintaining occupant comfort, outdoor air serves to dilute infectious aerosols, such as Mycobacterium tuberculosis droplet nuclei that are responsible for $\mathrm{TB}$ transmission.

Since the TB outbreak began, the shelter has taken numerous steps to improve administrative controls, particularly when it comes to identifying guests showing signs and symptoms of TB. We recommend additional improvements to the administrative and environmental controls at the shelter. From a ventilation standpoint, we suggest that all occupied spaces at the shelter complex be supplied adequate amounts of outdoor air, as prescribed by the Dallas Mechanical Code and ASHRAE standards. In addition, we identified an area that should be converted for respiratory separation purposes. This space could serve to separate a guest suspected of having $\mathrm{TB}$ or other respiratory diseases from the remainder of the guest population, 
until medical evaluation, transport or treatment could be obtained. We also recommend developing a written infection control plan, an HVAC operation and maintenance plan, and a written respiratory protection program. Having these plans/programs in place will help the shelter under normal operating conditions, and especially during future outbreaks of respiratory disease.

\section{Introduction}

Since the middle of 2009, Dallas County (TX) has experienced an increase in the number of epidemiologically-linked cases of tuberculosis (TB). Molecular analyses conducted by the CDC identified two separate clusters of TB in the community, and both clusters are disproportionately affecting the Dallas-area homeless community. Since September 2009, 58 TB cases belonging to the G10508 genotype cluster have been identified. Of those 58 cases, 43 (74\%) had a recent history of homelessness in Dallas-area homeless shelters. Since June 2009, 37 TB cases belonging to the G10509 genotype cluster have been identified, with 21 (57\%) reporting recent homelessness.

The Texas Department of State Health Services and Dallas County Department of Health and Human Services (DCHHS), with input from CDC, identified two Dallas-area homeless shelters as potential sites for ongoing disease transmission. As such, the DCHHS TB Elimination program has conducted several mass-screenings for TB disease at the two shelters and is working closely with the shelters (and others in the area) to identify and evaluate individuals potentially exposed to TB.

In additional response to the ongoing outbreak, a team of epidemiologists from the CDC National Center for HIV/AIDS, Viral Hepatitis, STD, and TB Prevention (NCHHSTP), Division of Tuberculosis Elimination (DTBE) conducted an on-site investigation in January, 2013. In their report dated April 10, 2013, the CDC team included a recommendation to improve environmental controls at the homeless facilities implicated in disease transmission. On March 21, 2013, the Division of Respiratory Disease Studies (DRDS), National Institute for Occupational Safety and Health (NIOSH), CDC received a request for technical assistance concerning the TB outbreak in Dallas County. The request was made by the Chief Epidemiologist of the DCHHS. The request specifically asked NIOSH to evaluate shelters' heating, ventilation, and air-conditioning (HVAC) systems and make recommendations to improve overall environmental controls. The request was initially made for an assessment at another Dallas area homeless shelter. However, after subsequent discussions with DCHHS, a request for technical assistance was received by DRDS/NIOSH/CDC from the shelter manager of this second shelter on May 22, 2013. Thus, a total of two requests were received to assess facilities that provide assistance to the homeless and which had epidemiologic links to past or ongoing TB transmission.

In response to the two requests for technical assistance, a NIOSH team visited the two facilities in June 2013. This report describes the measurements and associated findings from our assessment at the second homeless shelter. It details and prioritizes our recommendations 
for improving environmental controls at the shelter and outlines the current plan for future NIOSH involvement.

\section{Background}

\section{Tuberculosis and Homeless Populations}

TB is a disease caused by Mycobacterium tuberculosis (M. tuberculosis) bacteria. When a person with active TB disease coughs or sneezes, tiny droplets containing $M$. tuberculosis may be expelled into the air. Many of these droplets dry, and the resulting residues remain suspended in the air for long periods of time as droplet nuclei. If another person inhales air that contains the infectious droplet nuclei, transmission from one person to another may occur. Homeless people have been identified as a high-risk population for TB infection and disease since the early 1900s [Knopf 1914]. With the increase in homelessness in the United States since the 1980s, TB among homeless persons has become a subject of heightened interest and concern [CDC 1985; 1992; 2003a,b; 2005a; Barry et al. 1986; Slutkin 1986; McAdam et al. 1990; Nolan 1991].

\section{The Homeless Shelter}

The homeless shelter, located in downtown Dallas, TX, was opened in May 2008, by the community's homeless coalition. Unlike many homeless facilities, the shelter consists of all recently-constructed buildings designed for the sole purpose of providing services to homeless persons. The shelter is a multi-purpose facility based on a unique public-private partnership. It is dedicated to serving homeless men and women ( $\geq 18$ years old), with the primary focus being the chronically homeless. Any adult client may access shelter services after obtaining a unique shelter identification code, as long as the client does not have active arrest warrants with law enforcement agencies.

The large shelter campus is home to three main buildings and a large sleeping pavilion, which was converted from an old warehouse. In the center of the campus is a courtyard that features large fans, benches and water fountains. The welcome building is an approximately 10,000 square foot, one-story brick building that houses an intake area, a main reception area, counseling offices, a security office, library, laundry room, a women's day room, a phone room, a personal care area, and men's and women's restrooms. The welcome building provides care management services for more than 600 people experiencing homelessness per week, including: jail diversion/reentry services, income seeker services, and housing seeker services. All clients seeking services at the shelter must be processed through the welcome building.

The campus is also home to a 6700 square foot, one-story brick dining building that contains a kitchen, separate small and large dining rooms, men's and women's bathrooms, and men's and women's shower rooms. The dining building currently serves three meals a day, seven days a week to more than 700 people per meal. 
The largest building on the campus is a three-story, 40,000 square foot, brick and glass services building. The first floor of the building contains medical clinic facilities, including a waiting area, admission area, six examination rooms, counseling offices, nursing office, and restrooms. The first floor also houses a behavioral clinic waiting, admission, and conference room areas, as well as several staff offices, classrooms, and additional restrooms. Combined, the clinics provide medical and behavioral care for more than 600 people per week, including: screenings, acute disease care, chronic disease care, mental health/chemical dependency/dual diagnosis services, and recovery services. The second floor of the services building contains the women's transition dormitory rooms, a kitchenette, as well as a pair of day rooms and restrooms for the women housed there. The women's dormitory area is equipped to sleep 26 clients nightly. The second floor also houses many client counseling offices and offices for shelter administrators. The third floor of the services building contains the men's transitional housing units and subsequent day rooms and bathrooms, as well as the handicap housing area and handicap restrooms. The men's transitional housing units are equipped to sleep a total of 74 men, up to 14 of which can be housed in special handicap-accessible accommodations.

The sleeping pavilion is an 8600 square foot area with 17 -feet tall ceilings. During the day this area is utilized by clients as a place to rest and relax while waiting for other shelter service appointments. At night, the pavilion accommodates up to 225 people sleeping on mats. Both men and women sleep in the pavilion, but in separate areas of the room. Men's and women's restrooms with shower facilities are also available to clients in the pavilion area of the campus.

Each day, the shelter provides services to approximately 800-850 people. Each night, around 325 clients spend the night on campus, while nearly 500 others are placed in other Dallas-area shelters for the night. During periods of inclement weather, an additional 150 clients can be sheltered for the night in overflow areas at the shelter.

\section{Assessment}

On June 3, 2013, an opening meeting was held at the DCHHS. An update was given on the current status of the ongoing TB outbreak among the homeless population, and the assessment team provided background information on NIOSH, the nature of the technical assistance requests, and the ventilation measurements we planned to collect at each facility. Aside from NIOSH and DCHHS staff, representatives from each homeless facility we planned to visit during the week were present, as well as a representative from Parkland Hospital in Dallas, TX.

We arrived at the homeless shelter on Wednesday, June 5, 2013, and were met by the chief services officer, who briefly showed us around the campus and gave us an overview of the buildings on site and the services they provided. We were then introduced to the shelter manager who led us on a complete in-depth tour of the shelter campus. At the conclusion of the tour, we were introduced to the facilities director who served as our point of contact for the rest of our on-site assessment. 
We took physical and ventilation measurements in all key areas of the campus, focusing on areas where shelter clients typically congregate or spend significant amounts of time. The dining areas, main reception areas, and dormitory and day rooms were the areas of primary concern. However, we took measurements throughout every building on campus.

We recorded the make and model number of all six air-handling units (AHUs) providing supply air to the buildings on campus: three AHUs on the roof of the services building, two AHUs on the roof of the dining building, and one AHU on the roof of the welcome building. We also visually inspected all of the units. When possible, we measured the air flow rate through supply diffusers and return grilles using either a TSI Incorporated (Shoreview, Minnesota) Model EBT731Alnor Balometer Capture Hood or a Model 8373 Accubalance Plus Air Capture Hood equipped with appropriately-sized capture hoods for the vents/grilles being measured. The Model EBT731 measures volumetric air flow rates of 25-2500 cubic feet per minute $(\mathrm{cfm})$ with an accuracy of $\pm 3 \%$ of the reading plus $\pm 7 \mathrm{cfm}$ for measurements above $50 \mathrm{cfm}$, while the Model 8373 measures volumetric air flow rates of 30-2000 cubic feet per minute $(\mathrm{cfm})$ with an accuracy of $\pm 5 \%$ of the reading and $\pm 5 \mathrm{cfm}$. Both air capture hood models are equipped with a directional air flow indicator that provides confirmation of flow direction. We determined the approximate internal volume of the measured spaces with either a standard tape measure or a Zircon Corporation (Campbell, California) Model 58026 LaserVision DM200 laser distance measuring device. The device accurately measures up to 200 feet and has function keys for calculating the area and volume of a room for HVAC load formulas. When the existence of air flow or the air flow direction was questioned, we used a Wizard Stick hand-held fog generator (Zero Toys, Concord, Massachusetts) to qualitatively confirm and visualize the air flow pattern.

We completed taking measurements at the shelter campus on Thursday, June 6, 2013. On the morning of Friday, June 7, 2013, we met briefly with the services director, facilities director, and shelter manager to discuss our general findings from the assessment. An in-person, formal closing meeting for our on-site response to the technical assistance requests for both homeless facilities was not practical at the time of our visit. Thus, a meeting was held via teleconference on Wednesday, June 12, 2013. This meeting provided an opportunity to discuss our general findings with representatives from the DCHHS staff.

\section{Results and Discussion}

\section{General Tuberculosis Infection Control}

All tuberculosis control programs should include three key components: administrative controls (e.g., intake questionnaires and policies), environmental controls (e.g., ventilation and filtration), and a respiratory protection program. Ideally, environmental controls and respiratory protection should supplement aggressive administrative controls. Detailed explanations for each of these key control elements, as well as a discussion on the hierarchy of their implementation, are outlined in CDC's Guidelines for Preventing the Transmission of Mycobacterium tuberculosis in Health-Care Settings, 2005 and Prevention and Control of Tuberculosis in Correctional and Detention Facilities: Recommendations from CDC [CDC 
2005b, 2006]. In high risk environments, such as homeless shelters, or in areas where administrative controls alone are inadequate, environmental controls and respiratory protection should be used as secondary and tertiary levels of control, respectively.

\section{Administrative Controls}

During our visit, and in previous conversations with representatives from DTBE, the Texas Department of State Health Services, DCHHS, and the shelter, it was apparent that limited TB administrative controls were in place at the shelter prior to the current disease outbreak. Men and women placed in the transitional housing units were required to undergo TB testing prior to receiving a bed in the services building. However, little TB testing was conducted on the more transient client population prior to the outbreak. Since then, efforts were taken to improve the overall administrative controls in place by the time of the NIOSH site visit. Employees and volunteers were trained on symptoms of TB disease and prevention of TB transmission. Additionally, intake screening procedures are now in place to help identify guests on target screening lists, or others suspected of having TB, and refer them to DCHHS for critical medical screening. These procedures will help identify infected individuals more rapidly in the future and serve to help keep infected guests away from those that are not infected.

We cannot overstate the importance of having robust administrative controls in place. As with most homeless facilities, this shelter provides services to a large number of clients who are often in very close proximity to one another. This is particularly the case in the pavilion sleeping area, the dining areas during meals, and the main reception area of the welcome building during periods of occupancy. Even the best ventilation systems are incapable of preventing the spread of infectious disease between clients close to one another, as is often the case. Thus, promptly identifying people with suspected disease, keeping them separated from the general client population, and following up with appropriate medical evaluations and treatment (if necessary) are the most important elements of reducing or eliminating the spread of infectious disease.

While enhancing administrative controls is a significant step, the development of a written TB Infection Control Plan (ICP) for the shelter should be considered. At the time of the NIOSH investigation, no such ICP was reported to exist. Information on creating ICPs and useful TB ICP templates, although not specific to homeless shelters, can be found at the Curry International Tuberculosis Center website at http://www.currytbcenter.ucsf. edu/. Collaborating with DCHHS and the Texas Department of State Health Services would serve to further strengthen the written plan. These ICPs are particularly useful when overall TB infection control requires the coordination and subsequent follow-up of different agencies. In response to this current TB outbreak, there was good communication and coordination between the shelter and DCHHS. However, the process should be formally documented in a protocol or checklist format. This ensures that each time there is a TBrelated incident, all necessary agencies understand their responsibilities and perform their assigned predetermined actions in a consistent manner. A written TB ICP should be created, understood, and adhered to by all necessary agencies. Incorporating the input of staff 
involved in the maintenance and operation of facility ventilation systems into the overall infection control program can also help strengthen the program. Participation in plan development provides these staff members with additional insight as to what ventilation requirements are necessary to prevent and/or isolate TB disease and helps to ensure that ventilation modifications outlined in the plan are feasible. Input from the ventilation staff should be sought during the formal creation of the ICP and during all subsequent revisions to the plan.

\section{Environmental Controls}

General Ventilation System Information

General information on the AHUs at the shelter, including the areas served by each unit, is provided in Table 1. All six of the AHUs were rooftop units produced by McQuay International (Minneapolis, Minnesota). All of the AHUs were installed during construction of the campus and were 6-7 years old during our visit. The units provided cooling via a closed chilled water loop throughout the campus and heating through a separate hot water loop. A large chiller and multiple boilers are located on campus to support the AHU cooling and heating loads. All of the AHUs were controlled by a modern building automation system, including economizer cycles to adjust the amount of outdoor air brought into the buildings with changes in outdoor environmental conditions. Economizer cycles should generally be used to meet outdoor air requirements to each occupied space under all environmental conditions, while maximizing the amount of outdoor air when conditions make it economically feasible (i.e., when outdoor conditions are very close to desired indoor temperature and humidity setpoints).

\section{Filtration}

All six of the shelter AHUs contained sets of properly-sized, four-inch thick disposable panel filters from Glasfloss Industries (Dallas, Texas). The Glasfloss Z Line disposable panel filters have a published Minimum Efficiency Reporting Value (MERV) of 8. For ventilation air filters, the MERV value provides information on the overall filtration efficiency. A MERV 8 filter corresponds to a single-pass removal efficiency of greater than $70 \%$ for 3.0 to 10 micrometer $(\mu \mathrm{m})$ particles [ANSI/ASHRAE 2012]. However, MERV 8 filters are less than $50 \%$ efficient at filtering particles in the 1.0-3.0 $\mu \mathrm{m}$ size range, which includes droplet nuclei responsible for $M$. tuberculosis transmission [ANSI/ASHRAE 2012].

When part of a $M$. tuberculosis infection-prevention strategy, air filters should provide a removal efficiency of greater than $90 \%$ of particles in the $1.0-3.0 \mu \mathrm{m}$ size range, which corresponds to a MERV 13 or higher. During future HVAC design modifications, system evaluations, or retrofits, the selection of filters for use in the AHUs should be closely examined for the potential to increase filtration efficiency. However, care should be taken when choosing more efficient filters, because increased efficiency is typically associated with increased pressure drop across the filter (resistance to air flow). Filters in the AHUs should have the highest possible efficiency (i.e., highest MERV rating) while still maintaining the air flow required for conditioning and outdoor air supply through each system. 


\section{Preventive Maintenance}

The ventilation system preventive maintenance program at the shelter was coordinated by the facility director. All of the AHUs appeared clean, functional, and well maintained. Ventilation filters were reported to be changed monthly. Filter changes and other typical AHU maintenance tasks are addressed by maintenance staff employed by the shelter. Outside ventilation contractors are also brought in when necessary. Overall, the effectiveness of the HVAC preventive maintenance program was impressive, but there was no written plan outlining the preventive maintenance schedules and procedures for the shelter HVAC systems. A written HVAC Operation and Maintenance (O\&M) Plan should be developed. Combining all maintenance tasks, schedules, procedures, and training requirements into a written plan would help ensure that all equipment is properly maintained at appropriate time intervals and that any emergency maintenance issues are addressed correctly. Consultation with the filter media manufacturer or their vendor representative(s) should provide the recommended filter replacement frequency for inclusion into the O\&M plan. A detailed plan would also help ensure that the quality of work remains consistent as staff changes over time. Once developed, this written plan should be revised periodically to be current with any ventilation system and equipment modifications at the facility.

Ventilation Measurements and Indoor Air Quality

An adequate supply of outdoor air, typically delivered through the HVAC systems, is necessary within indoor environments to dilute pollutants that are released by equipment, building materials, furnishings, products, and people. Chapter 55, Dallas Mechanical Code, of the Dallas City Code regulates the "design, construction, quality of materials, erection, installation, alteration, repair, location, relocation, replacement, addition to, use, and maintenance of mechanical work in the city." The most recent version of the Dallas Mechanical Code took effect on November 1, 2013 (after the NIOSH visit). That version of the Dallas Mechanical Code adopted the 2012 edition of the International Mechanical Code, with some minor Dallas-specific changes and amendments [City of Dallas 2013; ICC 2012]. When it comes to ventilation standards, in most cases, the Dallas Mechanical Code has adopted the same recommendations published in American National Standards Institute (ANSI)/ASHRAE Standard 62.1-2010: Ventilation for Acceptable Indoor Air Quality (which was in effect at the time of the NIOSH survey) and carried over into the more recent ANSI/ASHRAE Standard 62.1-2013. These ASHRAE recommendations provide specific details on ventilation requirements for acceptable indoor air quality in a variety of indoor, occupied spaces [ANSI/ ASHRAE 2013a].

The Dallas Mechanical Code and ASHRAE 62.1-2013 recommend outdoor air supply rates that account for both people-related and building-related contaminant sources. Specific exhaust air flow rate requirements for some spaces are also listed. Although there are no specific guidelines for homeless shelters and related facilities, there are applicable published guidelines. These outdoor air supply and exhaust air requirements are summarized in Table 2. Table 2 also lists the default occupant densities for various spaces. These default values, given in terms of the number of occupants per 1000 square feet, are provided by the Dallas Mechanical Code and ASHRAE to assist building and HVAC system designers when actual occupant densities are unknown. Although actual occupant densities for the occupied spaces at the shelter 
are generally known, the default values still serve as a reference to determine whether the occupant density in a given space is higher or lower than what is considered typical.

The collected physical and ventilation measurements are presented in Table 3. The third column from the right of the table presents the actual occupant densities in each space. Values preceded by an asterisk $\left(^{*}\right)$ denote areas with occupant densities higher than the default values presented in Table 2 . High occupant densities are not solely indicative of ventilation problems and each case must be examined individually. For example, the pavilion sleeping area shows a high occupant density because many people actually sleep in close proximity to one another. Several of the offices and the library in the welcome building, and many offices throughout the first floor of the services building (including those in the two clinics) also show high occupant densities. Much of this is because the offices are smaller than what is considered typical. For private offices this would be less of a concern, however, many of these areas also represent spaces where shelter staff members could be face-to-face with a potentially infectious client. In these cases, special consideration should be given to air flow patterns in the spaces to minimize the potential of exhalations from one person passing through the breathing zone of multiple other people. This is especially true when airborne infectious disease transmission is a concern.

The second-to-last column in Table 3 presents the outdoor air requirements for each space, as established by the Dallas Mechanical Code and ASHRAE. As previously noted, all of the AHUs at the shelter are capable of introducing outdoor air into the occupied spaces they serve and the amount of outdoor air is controlled by an economizer cycle through the building automation system. During our assessment of the shelter AHUs, the outdoor temperature was nearly $90^{\circ} \mathrm{F}$, and the outdoor air dampers on all of the systems were nearly closed, if not closed completely. We did not have instruments that allowed us to accurately quantify the amount of outdoor air introduced by each AHU but given the damper positions, the amount of outdoor air supplied by each AHU appeared to be consistently less than that prescribed by the Dallas Mechanical Code and ASHRAE.

One area of heightened concern was the pavilion sleeping area, since it is not ventilated by a mechanical ventilation system. Throughout the campus, the potential for airborne disease transmission was of greatest concern in this space given that 225 people (or more) sleep on mats in close proximity with limited control over ventilation. The space does include two large ceiling fans to help move air and one wall has garage doors with windows removed to allow for natural ventilation (even more when the garage doors are raised). Regardless, there was no way to verify that appropriate amounts of outdoor air are introduced and well distributed throughout the space during periods of high occupancy and under all environmental conditions. During our visit to the shelter, we were told that a capital improvement project was planned that would install a mechanical ventilation system in the pavilion sleeping area. As of February 24, 2014, a new 50-ton AHU has been installed on the roof of the pavilion. Installation of ductwork and electrical systems was still ongoing. Assuming the new AHU was properly sized to handle conditioning outdoor air under all occupancy and weather conditions, then adequate fresh, outdoor air could be supplied to the pavilion sleeping area once the system is operational. It will be key however that this outdoor air be distributed down low, to the occupied floor area, in order to be of benefit to room occupants. 
It is important to ensure that all occupied spaces at the shelter are receiving adequate amounts of outdoor air to inhibit airborne disease transmission and improve indoor air quality. In addition to alleviating odors and better maintaining occupant comfort, outdoor air serves to dilute infectious aerosols, such as $M$. tuberculosis droplet nuclei. While the capacity to introduce and temper (i.e., heat or cool and dehumidify) appropriate amounts of outdoor air appeared to exist within each AHU, that capacity was not being properly used at the time of our assessment. Each AHU should be assessed to ensure that adequate capacity does exist to temper the recommended amounts of outdoor air under all periods of occupancy and all weather conditions. If so, making necessary adjustments to the HVAC sequence of operations could easily ensure sufficient outdoor air to the occupied spaces at all times.

If the capacity to temper sufficient outdoor air does not exist as the AHUs are currently configured, then one of two common approaches could be employed to introduce outdoor air into the occupied spaces (or a combination of the two). The first approach would be to make the necessary modifications to the existing AHUs to allow them to bring in the required outdoor air. This would initially require evaluation, by a knowledgeable HVAC engineer (a reputable ventilation or engineering design contractor that is familiar with ASHRAE, Facility Guidelines Institute [FGI], and CDC guidelines and recommendations), of each AHU's current conditioning capacity and the amount of additional capacity needed under worst-case conditions of occupancy and weather. Once that information is known, various modifications to each AHU can be compared to determine the most cost-effective method for meeting outdoor air requirements. Potential modifications could range from new cooling and heating coils, modifications to operating temperatures in the water supply loops, new fans, or some combination of these options. Although incorporating outdoor air into the existing AHUs may be the simpler of the two solutions and could require the least capital expense, it may cost significantly more in energy over time. At least on hot days, as was the case during our assessment, the AHUs are mainly recirculating air that is relatively close to the desired indoor temperature and humidity conditions (since only minimal outdoor air was brought in). After circulating through the occupied space, this air requires less conditioning to return it to the desired delivery temperature and humidity levels. Once significantly more outdoor air is mixed with the room return air, the mixed air stream passing through each AHU will be further from the desired indoor conditions for most of the year. Each AHU will then need to work harder to temper the mixed air stream.

A second method of bringing outdoor air into the shelter would be to install dedicated outdoor air systems. This would involve installing a new AHU for each building, with ductwork extending to all occupied spaces and dedicated specifically for supplying outdoor air. For the welcome building, the new AHU should be sized to provide adequate outdoor air flow for the entire building (approximately $1500 \mathrm{cfm}$ ) while also providing the entire capacity to temper and dehumidify this outdoor air. Similarly, the new AHUs for the dining building, services building, and pavilion would need to provide around $1500 \mathrm{cfm}, 3700 \mathrm{cfm}$, and 2000 cfm of outdoor air, respectively. The new AHUs should provide tempered and dehumidified (supercooled to $45-50^{\circ} \mathrm{F}$ dew point) outdoor air to each space (or existing AHU) in quantities necessary to meet Dallas Mechanical Code and ASHRAE outdoor air requirements under worst-case conditions. Terminal reheating or blending of this air with air delivered by 
the primary AHUs may be necessary to prevent thermal discomfort from the supercooled outdoor air. Conversely, multiple smaller dedicated outdoor air systems could serve the same purpose as one large system for a given building. For example, three small dedicated outdoor air systems could be used in the services building, with each tailored to serve only one floor. Regardless of how it is accomplished, the primary advantage of the dedicated outdoor air systems is that they would not require major modifications to the existing AHUs, which would continue to recirculate air through the spaces they serve while providing air filtration, heating and cooling. In fact, if the dedicated outdoor air systems are designed properly, all of the heating and cooling loads for the required outdoor air could be transferred to the new AHUs. This would allow the outdoor air intakes in the existing AHUs to be closed permanently. The dedicated outdoor air system approach would certainly require more capital expense and more renovations for the required ductwork than the first option, but they could also provide significant energy cost savings, making it a more viable long-term solution.

A knowledgeable HVAC engineer should be consulted to discuss these and other potential options for introducing outdoor air into all buildings on the shelter campus. At the same time, consideration should be given to optimizing air flow patterns to further protect shelter staff from the potential of airborne disease transmission. This is particularly important around reception areas in the welcome building and the two clinics in the services building, where staff members could come into close contact with guests having unknown cases of disease. While even the best ventilation system cannot guarantee prevention of disease transmission between people in close proximity to one another, improving air flow patterns could help reduce the overall transmission potential. One way that air flow patterns could be improved in these areas is to supply all air (fresh and recirculated) above the reception desks using supply diffusers designed to discharge the air in a wide, downward deflected angle. At the same time, return grills should be moved away from the reception desk to facilitate the flow of air from clean areas (the reception desks) to potentially contaminated areas (waiting areas). A qualified HVAC/ventilation engineer might recommend other air flow schemes that could be similarly effective at providing adequate ventilation while minimizing the potential for disease transmission. The final chosen design scheme should be smoke tested to verify performance.

During our visit, we collected measurements in the six medical clinic examination rooms on the first floor of the services building. Along with the clinic waiting area, these medical exam rooms are primary locations where sick and/or infectious clients might be present as they seek diagnoses or treatment from medical staff. As such, the waiting area and exam rooms should be constantly maintained under negative pressure to the adjacent admissions area and corridor, and the pressure relationship should be periodically tested and confirmed with a micromanometer or qualitative visual techniques like smoke tubes or flutter strips. Our measurements show (see Table 3), and ventilation fog testing confirmed, that the waiting area, and exam rooms \#1, \#2, and \#5 were improperly under positive pressure compared to the adjacent waiting area. Thus, air from inside these areas was able to migrate out into the adjacent spaces. Modifications to the ventilation system should be made to create proper air flow patterns so that airborne infectious agents generated inside these spaces are maintained inside the space. The correct negative pressure could possibly be established by adjusting 
existing dampers or ductwork so more air is exhausted from the exam rooms than is being supplied to them. Reducing return air and/or increasing supply air from adjacent areas on the same HVAC system could further facilitate this approach. If negative pressure cannot be maintained with such adjustments, the installation of dedicated exhaust fans within each exam room may be required. Depending upon the frequency of patient exams, the dedicated exhaust fan approach could be a more energy-efficient option for maintaining negative pressure in these areas, as they could be turned on and off as necessary. However, prudent administrative or occupancy-automated procedures to ensure their use during patient exams would be of primary importance.

The last column in Table 3 provides the recommended exhaust flow rates from occupied spaces, when such recommendations exist. Values in this column preceded by an asterisk $\left(^{*}\right)$ denote areas where the measured exhaust flow rates were less than the recommended rate as presented in Table 2. We noticed that exhaust air from most of the bathrooms and shower rooms throughout the campus was less than recommended by the Dallas Mechanical Code and ASHRAE (see Table 3). In fact, the south bathroom (Rooms S208 and S215) for the women's transitional housing dorms and the bathrooms for Unit B and Unit C in the men's transitional housing units were the only ones exhausting appropriate amounts of air from the spaces. The bathroom facilities for the guests staying in the pavilion did not have mechanical ventilation and did not appear to possess a reliable natural ventilation design scheme. To control humidity and odors, bathrooms and shower areas should exhaust more air than the AHU is supplying. This will maintain these areas under negative pressure. Separate exhaust fans should be used to exhaust air directly outside at least 25 feet from any air intakes. There should be no recycling or re-entrainment of return/exhaust air from the bathrooms and shower rooms. For high occupancy public bathrooms, the Dallas Building Code and ASHRAE Standard 62.1-2013 both include the same exhaust recommendations, but they differ in how the recommendations are applied. The Dallas Building Code states that if the exhaust fans are operated continuously, $50 \mathrm{cfm}$ per water closet should be exhausted. If the exhaust fans are operated intermittently (e.g., fans activated by a light switch), $70 \mathrm{cfm}$ per water closet should be exhausted. The ASHRAE Standard 62.1-2013 recommendation for public bathrooms is based on expected usage. It states that $70 \mathrm{cfm}$ per water closet should be exhausted when periods of heavy use are expected to occur. If periods of heavy use are not anticipated, then exhausting $50 \mathrm{cfm}$ per water closet is sufficient. For private toilets in bathrooms intended to be occupied by only one person at a time, both codes specify that the exhaust ventilation should be $25 \mathrm{cfm}$ if the exhaust fan is designed to operate continuously or $50 \mathrm{cfm}$ if the exhaust fan only operates during periods of occupancy (e.g., exhaust fan controlled by a wall switch). The exhaust fans in all bathroom and shower areas on the shelter campus should be checked to ensure functionality and their exhaust rates should be verified for compliance with the Dallas Mechanical Code. [Note: The kitchen hood exhaust systems in the dining building were not evaluated at the time of the NIOSH site visit. These systems are not discussed in this report.]

While not a major concern from an airborne disease transmission standpoint, temperature and relative humidity $(\mathrm{RH})$ affect the perception of comfort in an indoor environment. The perception of thermal comfort is related to one's metabolic heat production, the transfer of 
heat to the environment, physiological adjustments, and body temperature. Heat transfer from the body to the environment is influenced by factors such as temperature, humidity, air movement, personal activities, and clothing. ANSI/ASHRAE Standard 55-2013: Thermal Environmental Conditions for Human Occupancy specifies the combinations of indoor thermal environmental and personal factors that produce acceptable thermal environmental conditions to a majority of occupants within a space [ANSI/ASHRAE 2013b]. Assuming slow air movement (less than 40 feet per minute) and 50\% RH, the operative temperatures recommended by ASHRAE range from $68.5^{\circ} \mathrm{F}-75^{\circ} \mathrm{F}$ in the winter, and from $75^{\circ} \mathrm{F}-80.5^{\circ} \mathrm{F}$ in the summer. The difference between the two temperature ranges is largely due to seasonal clothing selection. ASHRAE also recommends that RH be maintained at or below 65\% [ANSI/ASHRAE 2013b]. The U.S. Environmental Protection Agency recommends maintaining indoor relative humidity between $30-50 \%$ because excessive humidity can promote the growth of microorganisms [EPA 2012]. Temperature and RH levels were not recorded during our visit. Regardless, we recommend maintaining the indoor temperature and $\mathrm{RH}$ levels within the ranges established by ASHRAE to provide the most comfortable environment to shelter clients.

\section{$\underline{\text { Respiratory Separation Areas }}$}

Currently, the shelter does not have areas set aside for separating clients suspected of having TB or other respiratory diseases from the remainder of the guest population. Rapidly identifying people with suspected TB disease and keeping them separated from others until appropriate medical evaluations and treatments are initiated is one of the most important elements in reducing or eliminating the spread of airborne disease. Excluding those clients in the transitional housing units, the background and medical status may be largely unknown for guests seeking shelter in the pavilion sleeping area. Given this fact, as soon as the new mechanical ventilation system is installed and operational, we strongly recommend creating an area inside the pavilion (or some other suitable location) which can be used for respiratory separation when needed. It is important to recognize that respiratory separation is not an alternative to medical evaluation. Rather, it is proposed to be a temporary holding area for guests awaiting transport for medical evaluation. It may also be used to house guests exhibiting signs of respiratory distress without having identified disease. When respiratory separation is not required, the areas can be used for normal clients' housing, as is typically the case.

A respiratory separation area is not intended to be equivalent to an airborne infection isolation (AII) patient room found in hospitals and other healthcare settings. However, it can be designed using some of the same protective concepts, namely negative room pressure and elevated ventilation rates. The respiratory separation area should be maintained under negative pressure relative to the adjacent spaces. This means that air from outside the respiratory separation area should migrate inwards into the respiratory separation area and not in the opposite direction. This is easily maintained by exhausting more air from the respiratory separation area than is being supplied. Operable windows, either within the respiratory separation area or in adjacent areas, should not be allowed to interfere with this intent. Negative pressure helps reduce the potential that a guest housed in the respiratory separation area with active TB disease (or any other disease where airborne infection is a 
concern) could expose other healthy individuals in adjacent areas. In addition to maintaining negative pressure, all return air from the respiratory separation area should preferably be exhausted directly outside. In no circumstances should air from the respiratory separation area be allowed to re-infiltrate the building or go back through an AHU without first having passed through a high-efficiency particulate air (HEPA) filter.

For true AII rooms in healthcare facilities, the CDC and FGI recommend a differential pressure of $\geq 0.01$ inches of water gauge (2.5 Pascals $[\mathrm{Pa}]$ ) across the closed door between the isolation area and adjacent areas [CDC 2005b; FGI 2010]. Although the minimum pressure difference needed for maintaining airflow into a room is quite small (about 0.001 inches of water gauge), the higher prescribed pressure differential is easier to measure and maintain as the pressure in surrounding areas changes due to the opening and closing of doors, ventilation system fluctuations, and other factors. The FGI and CDC also recommend a total of 12 air changes per hour $(\mathrm{ACH})$ through the isolation room (CDC allows $6 \mathrm{ACH}$ for existing AII rooms) and at least $2 \mathrm{ACH}$ of fresh outdoor air. True AII rooms are designed to house individuals with confirmed respiratory disease. A respiratory separation area at the shelter would not be used to house guests with confirmed disease, so it would not be necessary to meet the strict air flow and differential pressure requirements detailed above. However, knowledge of the AII design strategies could be useful in designing a respiratory separation area. It is vastly more important to establish a negative pressure area that can be used for respiratory separation than it is to focus on the respiratory separation area meeting quantitative ventilation requirements.

Since the pavilion houses all guests in the same large, open sleeping area, ideally a small room, complete with its own solid ceiling, should be constructed in a far, rear corner (away from the wall that contains the garage doors) specifically for respiratory separation. Having a sealed, separate room would allow the space to be used for separation purposes by: 1) installing a new dedicated exhaust fan through the outside wall of the room to provide the required exhaust air flow when the room was in use for respiratory separation, and 2) installing tightclosing dampers (or some other mechanism) to completely seal all air returns from the room to the new pavilion AHU (if you would choose to provide mechanical ventilation to the space with the new pavilion AHU). An exhaust fan should be chosen that is capable of maintaining the room under negative pressure relative to the adjacent, larger pavilion sleeping area at all times, with minimal noise. The fan could be mounted directly in the wall or on the roof with ductwork running through the wall and up to the fans on the outside of the shelter. It is imperative that exhaust air from the new exhaust fans is directed away from all current/future AHU air intakes and gathering areas outside the shelter.

When a client checks in for night shelter and while presenting symptoms of respiratory disease, they should be allowed to sleep inside the new respiratory separation area until they can be evaluated by medical personnel. To prepare the room for respiratory separation, the room's dedicated exhaust fan should be activated to maintain the space under negative pressure. When respiratory separation is not required, the room can be used for another purpose (e.g., storing sleeping mats) by simply deactivating the exhaust fan. 
If construction of a separate room inside the pavilion is impractical, an alternative (but lessdesirable) approach is to install impervious retractable partitions (e.g. accordion-type room dividers) that could be used to enclose a far, rear corner of the sleeping area when respiratory separation is warranted. The partitions should touch the floor and extend as close to the roof deck as possible. An exhaust fan would need to be installed through one of the solid outside walls enclosed by the partitions. Again, the fan could be mounted directly in the wall or on the roof with ductwork running through the wall and up to the fan on the outside of the building. Since there would be more leakage into the separation area around the partition walls, and because of the high ceiling in the pavilion, a larger fan would likely be required to maintain negative pressure over that required for a solid room. One way to reduce the size of the exhaust fan would be to install a small false ceiling that the retractable partitions could seal around, thus reducing the overall volume of the separation area.

If a retractable partition enclosure is selected for respiratory separation, the partitions should fit as snug to the floor and ceiling as possible. The new exhaust fan should be activated to maintain the enclosed space under negative pressure any time the space is used for separation purposes. For the majority of the time, when respiratory separation is not required, the corner of the room can be used as normal by shutting down the exhaust fan and pushing the retractable partitions out of the way.

For any respiratory separation area, a written plan for testing and operating the space is strongly recommended. At the shelter, a detailed written plan should be developed for the rapid conversion of the space from standard usage to use for respiratory separation. The plan should include steps for cleaning and refurnishing the area for separation purposes, and stepby-step procedures for shelter staff to follow to effectively initiate respiratory separation.

When occupied for separation purposes, all respiratory separation areas should be visually tested daily to ensure negative pressure is being maintained. Testing can be done cheaply and easily with tissue flutter strips or smoke tubes. The results of the testing should be documented each day when in use. When the spaces are being used for other purposes, they should be tested a minimum of once per month to ensure proper operation in the event they would be needed for respiratory separation.

In addition to providing respiratory separation for a shelter guest staying overnight in the pavilion area, it could also serve as an area to temporarily separate a guest presenting in the welcome center with symptoms of disease during the day. If this arrangement is not feasible, a separate respiratory separation area could be established inside the welcome building itself.

\section{Auxiliary HEPA Filtration}

The higher the dilution ventilation rate within a given respiratory separation area, the faster the room air will be cleared of existing airborne pathogens. In order to increase effective ventilation within a separation area, in-room HEPA filtration units may be used. These units may be portable or permanently-mounted within the space. Some models can be ceiling mounted, which could reduce the potential for tampering. If such units are used, their placement and discharge orientation must be selected, installed, and maintained carefully 
to maximize room air mixing effectiveness without disrupting the desired flow of air into the respiratory separation area. These criteria become even more important if a retractable partition enclosure is used to establish a respiratory separation area.

One unique use of portable HEPA filtration units is through the use of a ventilated headboard. The ventilated headboard is a NIOSH-developed technology that consists of lightweight, sturdy \& adjustable aluminum framing with a retractable plastic canopy sheeting that can extend over the pillow area of a cot, mat or bed. Low-velocity airflow into the canopy is created using a high-efficiency fan/filter exhaust unit. This local control technique allows for near-instant capture of aerosol originating from the patient while simultaneously providing air cleaning to the entire room. NIOSH engineers are available to provide additional information or to assist in the selection and acquisition of ventilated headboards.

\section{Ultraviolet Germicidal Irradiation}

Ultraviolet germicidal irradiation (UVGI) is the use of ultraviolet (UV) energy (electromagnetic radiation with a wavelength shorter than that of visible light) to kill or inactivate viral, bacterial, and fungal organisms. The UV spectrum is commonly divided into UVA (wavelengths of 400-315 nm), UVB (315-280 nm), and UVC (280-200 nm). The entire UV spectrum can kill or inactivate microorganisms, but UVC energy provides the most germicidal effect, with $265 \mathrm{~nm}$ being the optimum wavelength [ASHRAE 2011, 2012]. Modern UV lamps primarily create UVC energy at a near-optimal $254 \mathrm{~nm}$ by electrical discharge through low-pressure gas (including mercury vapor) enclosed in a quartz tube. UVC from mercury lamps is often referred to as UVGI to denote its germicidal properties. Although UVC is invisible to the human eye, small amounts of energy released at visible wavelengths produce the blue glow commonly associated with UVC lamps.

Research has demonstrated that UVGI is effective in killing or inactivating M. tuberculosis under experimental conditions [Riley et al. 1957, 1962; Riley and Nardell 1989; Xu et al. 2003]. UVGI has also proven effective in reducing the transmission of other infectious agents in hospitals, military housing units, and class rooms [Willmon et al. 1948; Wells and Holla 1950; McLean 1961]. Due to the results of controlled studies and the experiences of clinicians and engineers, UVGI has been recommended as a supplement to other TB infection-control and ventilation measures to kill or inactivate M. tuberculosis [David 1973; Riley et al. 1976; CDC 2005b, NIOSH 2009].

Representatives from the shelter have reported that the new 50-ton AHU being installed above the pavilion sleeping area is equipped with an in-duct air disinfection system designed to inactivate $M$. tuberculosis as it travels through the ventilation system. Actual design details are unknown to NIOSH at this time; however, if appropriately designed and maintained, this in-duct UV system, coupled with particulate filtration, may provide a higher "effective" filtration rate than filters alone. The new in-duct UV system represents a prudent control that may help prevent the spread of airborne disease among clients in the pavilion sleeping area. The addition of a well-designed upper-room UVGI system could provide additional protection to pavilion clients at the shelter. In congregate settings typical in homeless shelters and healthcare facilities, upper-room UVGI systems (often called upper-air systems) are 
often used to interrupt the transmission of airborne infectious pathogens within the occupied spaces themselves. Upper-room UV lamp fixtures are suspended from the ceiling and/or mounted on walls at a minimum height of 7 feet above the floor (Figure 2) [Riley and Nardell 1989; Brickner et al. 2003; NIOSH 2009; ASHRAE 2011, 2012]. Lamps are shielded to direct radiation upward and outward to create an intense zone of UVC in the upper portion of the room while minimizing UVC levels in the lower occupied spaces. These fixtures inactivate airborne microorganisms by irradiating them as air currents move them into the path of the UV energy. Some upper-room lamp fixtures utilize small fans to enhance air mixing (right photograph in Figure 2) [First et al. 1999a,b; CDC 2005b; NIOSH 2009; ASHRAE 2011, 2012]. The overall effectiveness of upper-room UVGI systems improves significantly when the space is well mixed [Riley and Nardell 1989; Brickner et al. 2003]. Although convection air currents created by occupants and equipment can provide adequate air circulation in some settings, mechanical ventilation systems and/or ceiling fans that maximize air mixing are preferable. Floor fans can also be placed in the room to ensure adequate mixing.

Application and placement criteria for upper-room UV fixtures are provided in various publications, and manufacturer-specific advice on placement and operations should always be followed [First et al. 1999a,b; Riley and Nardell 1989; Brickner et al. 2003; CDC 2005b; NIOSH 2009; ASHRAE 2011, 2012]. For decades, a rule of thumb for upper-air installations has been one 30-watt (nominal input) fixture for every 200 square feet of floor space to be irradiated [Riley and Nardell 1989]. Many effective systems have been designed to this criterion, yet it is important to note that not all 30-watt lamps provide the same output of UVC energy. Ultimately, UVC output is dependent on the type of lamp, the lamp manufacturer, the ballast used to power the lamp, the complete fixture design, and other factors. A more recent study has suggested installing fixtures to maintain a uniform UV distribution of around 30-50 microwatts of UVC energy per square centimeter $(\mu \mathrm{W} /$ $\mathrm{cm}^{2}$ ) in the upper portion of the room [Xu et al. 2003]. While essentially "normalizing" the recommended output over all lamps and fixture designs, this level of irradiance should be effective at inactivating most airborne droplet nuclei containing Mycobacterium, and would presumably be effective for inactivation of most viruses as well. Using the results of the $\mathrm{Xu}$ et al. study, NIOSH developed guidelines for designing upper-room UVGI systems for controlling the spread of tuberculosis [NIOSH 2009]. While the guidelines were specifically targeted for healthcare settings, they are just as applicable to congregate sleeping areas in homeless facilities.

We recommend consulting with a qualified UVGI fixture manufacturer or system engineer, familiar with the NIOSH upper-room UVGI guidelines, to design and install an upper-air UVGI system in the pavilion sleeping area. The 17 -feet ceiling height in that space provides an excellent opportunity to utilize a variety of commercially-available fixtures to create a large irradiance zone in the upper portion of the room. The ability to mount the fixtures at higher heights will also help prevent the fixtures from being tampered with. The two large ceiling fans will also provide air mixing within the entire space that is critical for optimum upper-air UVGI system performance. Representatives from the shelter also reported that an upperroom UVGI system is currently being installed inside the large reception area in the welcome building. Another area where upper-air UVGI should be considered is the main large circular 
dining area in the dining building. Like the pavilion sleeping area, these spaces have relatively tall ceilings that would help maximize UVGI effectiveness while minimizing the likelihood of guests tampering with the lamp fixtures. All of the upper-air UVGI systems should be designed to provide UV irradiance levels of at least $30-50 \mu \mathrm{W} / \mathrm{cm}^{2}$ in the upper portion of the room while limiting UVC exposure to occupants in the space. If desired, NIOSH engineers are available to review proposed UVGI design strategies prior to their purchase and installation.

In humans, UVGI may be absorbed by the outer surfaces of the eyes and skin. Shortterm overexposure may result in photokeratitis (inflammation of the cornea) and/or keratoconjunctivitis (inflammation of the conjunctiva). The NIOSH Recommended Exposure Limit (REL) for ultraviolet irradiation $(254 \mathrm{~nm})$ is 6.0 millijoules per square centimeter $(\mathrm{mJ} /$ $\mathrm{cm}^{2}$ ) for an 8-hour exposure time [NIOSH 1972; ACGIH 2012]. This REL corresponds to a maximum continuous exposure of $0.2 \mu \mathrm{W} / \mathrm{cm}^{2}$ of irradiation to a person inside the room over the 8-hour period. If periods of longer potential exposures are anticipated, the measured UV irradiance in the lower portion of the room should be lower than $0.2 \mu \mathrm{W} / \mathrm{cm}^{2}$. The NIOSH guidelines clearly explain calculating permissible exposure times given actual irradiance levels in the occupied zone. Actual UVC irradiance levels in the occupied portion of the room, along with corresponding permissible exposure times, should be measured and documented by the system designer/installer prior to initial system use.

Once the upper-air UVGI system is in place and working properly, the fixtures should be operated any time occupants are in the pavilion sleeping area. It is preferable to operate the system 24 hours a day every day. As with any environmental control system, the new upperair UVGI system will require periodic maintenance. The output from UV lamps naturally decreases over time as the lamps are burned. Frequently turning the lamps off and on also shortens the useful life of the lamps. The UV output from lamps will also decrease due to accumulated dust. Therefore, lamps should be inspected periodically (e.g., quarterly) and cleaned when necessary. UV lamps are typically cleaned by wiping the lamp tubes with isopropyl alcohol (rubbing alcohol) and a clean, lint-free cloth. Cleaning the lamps with water can result in smearing of the dust that can further reduce lamp performance. The fixtures housing the UV lamps should be inspected and cleaned as well. Typical UVGI lamps are rated for around a year of continuous use. Lamps should be replaced annually, or in accordance with appropriate manufacturer recommendations.

IMPORTANT SAFETY PRECAUTION: All UVGI systems must be inactivated before workers enter the irradiated upper portion of the space. All maintenance personnel that might spend time in the pavilion sleeping area should be trained in exposure hazards posed by the UVGI fixtures. Employees responsible for lamp and fixture maintenance should receive additional safety training, including appropriate lockout/tagout procedures to prevent accidental UV exposures during maintenance tasks. All initial maintenance and training requirements should be explained by the UVGI system designer/installer. The required maintenance tasks and service logs, along with training requirements and logs should be included in the written O\&M plan recommended above. A subcomponent of this plan should include a UVGI safety plan. Complete information on upper-room UVGI system design, 
operation, maintenance, and safety can be found in the NIOSH guideline document available online at: http://www.cdc.gov/niosh/docs/2009-105/pdfs/2009-105.pdf [NIOSH 2009].

\section{Respiratory Protection}

During an outbreak of airborne infectious disease, there could be instances when shelter staff members or volunteers find themselves in close contact with guests suspected of being infectious. Ideally, these cases would be identified during the administrative screening process and appropriate precautions initiated, but when these circumstances cannot be avoided, it is wise to consider the availability of respiratory protection to protect staff and volunteers. The first step toward the implementation of respirator use is to develop a document that clearly outlines a formal respiratory protection program. The Occupational Safety and Health Administration (OSHA) Respiratory Protection standard (29 Code of Federal Regulations [CFR] 1910.134) outlines the requirements for comprehensive respiratory protection programs. In accordance with 29 CFR 1910.134, a written Respiratory Protection Program, with an identified program administrator, is required for any facility that requires employees to wear respirators. The program must include training, medical evaluations, and respirators at no cost to employees or staff required to wear respirators on the job. Initial fit testing by a trained individual is required for all employees that will potentially wear a respirator. Annual fit testing is required after that, with additional fit testing upon major changes to the facial features of the respirator user (i.e. major weight gain/loss, change in facial hair, scarring, etc.).

To comply with applicable OSHA regulations regarding respiratory protection, we recommend that the shelter create a written respiratory protection program as outlined in 29 CFR 1910.134, appoint a program administrator, and initiate training and initial fit testing for employees. Many online resources exist to assist in the development of a respiratory protection program. OSHA has published a Respiratory Protection informational booklet online (http://www.osha.gov/Publications/OSHA3079/osha3079.html) and a more detailed Small Entity Compliance Guide for the Revised Respiratory Protection Standard (http:// www.osha.gov/Publications/3384small-entity-for-respiratory-protection-standard-rev.pdf) to explain all parts of an appropriate respiratory protection program and how to comply. The Small Entity Compliance Guide also contains a sample respiratory protection program in Attachment 4 that can be used as a model program. The Washington State Department of Labor and Industries has also developed a user-friendly, fillable template that is helpful in developing a respiratory protection program at http://www.lni.wa.gov/Safety/Basics/ Programs/Accident/Samples/RespProtectguide2.doc.

The DCHHS, Texas Department of State Health Services, local healthcare facilities or fire/ ambulance stations can potentially assist with training and fit testing the employees required to wear respirators. Alternatively, qualitative fit testing kits $\left(\right.$ Bitrix $\left.^{\mathrm{Tn}}\right)$ can be purchased for around $\$ 200.00$ each. One kit would likely be enough to conduct all necessary fit testing at the shelter for an entire year or more. When paired with a trained and competent fit test administrator (see 29 CFR 1910.134), these kits would allow cost-effective, on-site fit testing annually. 


\section{Conclusions}

Since the increase in cases of TB disease in 2009, the shelter has taken significant steps to improve the administrative controls at the shelter. The shelter has developed important lines of communication with DCHHS and improved staff training and awareness of TB symptoms. Identifying guests with symptoms of TB disease or those listed on the DCHHS target screening lists will help further reduce the potential for future cases of TB disease and bring the ongoing outbreak under control. Having consistent protective strategies upon suspect case identification is also important. While enhanced administrative controls are now in place, there was no written ICP established for the campus, and shelter administrators are encouraged to promptly coordinate with DCHHS and the Texas Department of State Health Services to establish one.

Overall, the campus was clean and well maintained. From an environmental control perspective, the six rooftop AHUs servicing the welcome building, dining building, and services building were all operational, well maintained, and fitted with proper filter configurations during our visit. The HVAC preventive maintenance program in place at the shelter is managed by the current facility manager and his maintenance staff. While the results were impressive, developing a written preventive maintenance or O\&M plan for the shelter AHUs would further strengthen the preventive maintenance program, particularly as staff members change.

The amount of outdoor air distributed to each occupied space by each AHU is controlled by a modern building automation system, including economizer cycles. We were unable to accurately determine the amount of outdoor air being introduced by each AHU, but given the damper positions witnessed, the amount of outdoor air appeared to be less than that required by the Dallas Mechanical Code and ASHRAE guidelines. Additionally, the pavilion sleeping area was not ventilated by a mechanical ventilation system at the time of the NIOSH survey. Given the number of guests served at the shelter and the close proximity of guests to one another within many of the occupied spaces, it is important that these spaces consistently receive adequate amounts of outdoor air. In addition to alleviating odors and better maintaining occupant comfort, outdoor air serves to dilute infectious aerosols, such as M. tuberculosis droplet nuclei responsible for TB transmission. With renovations, the existing AHUs might be made to provide the necessary outdoor air, or they could be augmented with the installation of new, dedicated outdoor air systems to provide the necessary outdoor air. A knowledgeable HVAC engineer should be consulted to discuss options for introducing outdoor air throughout the shelter complex. At the same time, consideration should be given to improving the air flow patterns in the various living and sleeping areas within the complex. Once these changes have been implemented, other ventilation equipment and/or supplemental ultraviolet germicidal irradiation systems could be investigated if additional environmental controls are desired.

During our visit, we learned that the men and women housed in the transitional housing units on the second and third floors of the services building were required to undergo TB testing prior to placement in the program. However, the shelter did not have an area set aside 
for separating more transient, overnight guests suspected of having TB or other respiratory diseases from the remainder of the guest population. The background and medical status of these overnight guests may be largely unknown. Therefore, it would be prudent to modify an area in the pavilion sleeping area for use as a respiratory separation area in the event an overnight guest presented with symptoms of respiratory infection. When respiratory separation is not required, the area could be used for some other purpose.

The pavilion sleeping area houses approximately 225 guests, or more, nearly every night. Given the occupant density, along with the benefit of the 17-feet ceiling height, a complete upper-room UVGI system could be installed in the space to further reduce the potential for airborne disease transmission. A qualified UVGI system designer or fixture manufacturer should be consulted for options. The system should be designed, operated, and maintained in accordance with NIOSH guidelines available online at: http://www.cdc.gov/niosh/docs/2009105/pdfs/2009-105.pdf [NIOSH 2009]. Upper-air UVGI systems should also be considered for the main reception area of the welcome building and the large dining room in the dining building. Once all changes and improvements to environmental controls at the shelter have been implemented, the shelter should develop a written preventive maintenance or O\&M plan for the shelter.

For instances where improvements to administrative and environmental controls do not sufficiently mitigate the risk for disease transmission, respiratory protection might be necessary. There was no formal respiratory protection program in place during our visit, but such a program should be implemented at the shelter. Having this program in place will provide additional protection to shelter staff and volunteers working in close proximity to guests with suspected TB or other airborne diseases. All respirator use at the shelter should be covered by an OSHA-mandated respiratory protection program.

Administratively, a positive approach is being taken toward reducing the likelihood of future TB transmission at the shelter. However, the ventilation systems need some attention to further reduce the risk. While ventilation systems and other environmental control systems cannot guarantee prevention of future TB disease transmission, improving the environmental controls will reduce the potential for airborne disease transmission, along with providing better indoor air quality throughout each building. The following recommendations are aimed at improving the overall infection control program at the shelter, with emphasis on improvements to the existing environmental controls so they meet all applicable standards and guidelines.

\section{Recommendations}

Based on our assessment of environmental controls at the shelter, we have developed the following list of recommendations, in order of priority:

\section{Continue to improve and enhance the TB administrative controls at the complex and develop a written Infection Control Plan.}


- Continue working with the DCHHS to screen campus staff, volunteers, and guests for TB disease.

- With input from DCHHS, develop specific procedures for handling a suspected or confirmed case of TB disease.

- Continue educating staff and volunteers on the signs and symptoms of TB disease so they can readily identify suspect cases and implement established precautions.

- Consider displaying informational posters about TB signs and symptoms to educate guests.

- Consider displaying signs encouraging proper cough etiquette and hand hygiene.

- Develop a formal written TB Infection Control Plan. Seek guidance and input from DCHHS and the Texas Department of State Health Services. The plan should include:

- All aspects of the TB infection control program and associated responsibilities (to include reasonable scenarios of guests presenting with symptoms and associated response requirements), especially those functions requiring coordination with other agencies, such as the local and state health departments.

- The improved administrative controls put in place at the shelter since the beginning of the TB outbreak.

- Input from ventilation staff and/or guests tasked with servicing ventilation systems. Obtaining input from ventilation maintenance staff serves to strengthen the environmental control section of the plan while giving maintenance staff additional insight into the ventilation requirements for reducing or preventing airborne disease transmission.

- Schedule for updating and revising the ICP.

\section{Create a respiratory separation area in the pavilion sleeping area.}

- Choose a reputable ventilation or engineering design contractor that is familiar with current Dallas Mechanical Code, ASHRAE, FGI, and CDC guidelines and recommendations. Ideally a small enclosed room should be constructed in a far, rear corner of the sleeping area specifically for respiratory separation. If construction of a separate room is impractical, a less-desirable approach is to install impervious retractable partitions that could be used to enclose a corner of the sleeping area when respiratory separation is warranted. The partitions should touch the floor and extend as close to the ceiling as possible. While there are various ways to develop a respiratory separation area, it should include the following:

- Ensure that all supply and return ductwork for the AHU serving the newly-constructed room or area enclosed by partitions (if any) is intact and sealed. Install tight-sealing return dampers on each return from the room or enclosure (if any) to eliminate return air flow when the space is used for respiratory separation. Ensure that supply air diffusers provide good air mixing and air flow patterns in a newly- 
constructed room.

- Design and install an auxiliary exhaust system that enables the respiratory separation area to be maintained under negative pressure when housing guests for separation purposes. One approach to this requirement would be to select and install exhaust fans directly through the outside wall of the room or space enclosed by partitions. The fan can be mounted through the wall itself or mounted on the roof with ductwork through the wall to the fan.

- Install the highest efficiency air filters in the AHU that will still allow adequate airflow to meet the AHU's conditioning requirements. Adjust and balance the system as necessary to ensure proper air flows at all times when the room or curtain enclosure is used for respiratory separation and normal purposes. Ensure that adequate outdoor air is supplied to each space at all times (see Recommendation 7 below).

- Develop a detailed written plan for the conversion of the room or partition enclosure from normal functions to use for respiratory separation. The plan should include:

- Procedures for staff to follow to establish the respiratory separation area (if partitions are used), start the exhaust fan, close the return air dampers (if any), and test for negative pressure.

- Measures for preparing the area for back-to-back occupants requiring separation.

- Procedures for cleaning and returning the area to normal use after the need for respiratory separation has passed.

- Operate the new system as designed and according to the written plan. When in use, the respiratory separation area should be visually tested with smoke tubes or flutter strips daily to ensure negative pressure is being maintained while the space is occupied for separation. When the area is being used for normal purposes, it should be tested monthly to ensure proper operation in the event it would be needed for respiratory separation. The results of all pressure testing should be documented.

\section{Make necessary ventilation changes so all medical clinic examination rooms} are properly maintained under negative pressure in relation to the adjacent waiting area. Negative pressure might be established by adjusting existing dampers or ductwork so more air is exhausted from the exam rooms than is being supplied to them. If negative pressure cannot be maintained with such adjustments, the installation of separate exhaust fans from each space may be required. If new exhaust fans are required, they should be operated any time the examination rooms are occupied.

4. Repair, replace, or install new bathroom exhaust fans. Ensure that air is being exhausted from each bathroom and shower facility and that each area is under negative pressure, in accordance with the Dallas Mechanical Code and ASHRAE 
requirements. Ensure that all exhaust air from bathrooms and shower facilities is exhausted directly outside and that no return air from bathrooms is recirculated back to an AHU or entrained in the outdoor air entering any current or future AHU.

5. Develop a comprehensive, written HVAC O\&M plan. This plan should be updated as improvements to HVAC systems are being made. The O\&M Plan should include:

- Preventive maintenance schedules and all regularly scheduled maintenance tasks (filter changes, fan belt inspections, UV lamp changes, etc.) and who is responsible for conducting each task.

- Written procedures for each maintenance task to ensure the work is done properly each time, regardless of who performs the work.

- Training requirements for maintenance staff.

- A method for logging maintenance activities for each AHU.

- A method for updating or revising the O\&M Plan as procedures or systems change.

\section{Install an upper-room UVGI system in the pavilion sleeping area.}

- $\quad$ Choose a qualified UVGI fixture manufacturer or system engineer, familiar with the NIOSH upper-room guidelines, to design, install and test the system. The system designer/installer should also provide initial training on exposure hazards, safety, and system maintenance.

- $\quad$ The system should be designed to provide UV irradiance levels of at least $30-50 \mu \mathrm{W} / \mathrm{cm}^{2}$ in the upper portion of the room while limiting UVC exposure to occupants in the area to a level below the NIOSH REL for $\mathrm{UVC}$ of $6.0 \mathrm{~mJ} / \mathrm{cm}^{2}$ for an 8 -hour exposure time.

- $\quad$ Operate the upper-room UVGI system all day, every day, or at least at all times the pavilion is occupied.

- $\quad$ Establish a UVGI safety, operation, and maintenance program.

- $\quad$ Conduct training and maintenance in accordance with NIOSH guidelines (http://www.cdc.gov/niosh/docs/2009-105/pdfs/2009-105.pdf) [NIOSH 2009] and/or applicable manufacturer recommendations.

\section{Introduce the required amounts of fresh outdoor air to all occupied spaces under} all occupancy and environmental conditions.

- There are multiple options that can allow adequate outdoor air to be supplied to the occupied spaces of the campus. If capacity exists in the current AHUs, the easiest method would be to make necessary adjustments to the existing HVAC sequence of operations so that appropriate amounts of outdoor air are brought in at all times. Other options are also available and discussed in this report. All options, including the associated capital, maintenance, and annual operating costs should be considered. Work with a reputable ventilation or engineering contractor familiar with the current Dallas Mechanical Code, ASHRAE, FGI, and CDC guidelines to select the best option for the shelter.

- Improve air flow patterns within all occupied spaces, particularly around reception areas in the welcome building and the two clinics in the services 
building. Air flow patterns should provide effective ventilation and temperature control while flowing from clean areas to areas more likely to be contaminated.

8. Improve filtration efficiency in all AHUs. Select higher efficiency filters (higher MERV ratings) for use in each AHU, as long as the new filters do not adversely impact the required air flow delivery capacity of the AHUs.

\section{Develop and implement an OSHA respiratory protection program in accordance} with 29 CFR 1910.134. To meet the OSHA requirements, you must:

- Designate a program administrator who is qualified by appropriate training or experience to administer or oversee the program and conduct the required program evaluations.

- Provide respirators, training, and medical evaluations at no cost to employees or staff required to wear respirators on the job.

- Develop a written program with worksite-specific procedures when respirators are necessary or required by the employer. The written respiratory protection program needs to include:

- Respirator types and proper respirator selection.

- Required medical evaluations for employees prior to respirator use.

- Procedures for initial and annual respirator fit testing.

- Instructions for proper respirator use.

- Information on appropriate respirator maintenance and care.

- Initial and yearly training requirements for respirator users.

- Procedures for evaluating the effectiveness of the respiratory protection program.

- Update the respiratory protection program as necessary to reflect changes in workplace conditions that affect respirator use.

\section{Outline of Future NIOSH Involvement}

This report will serve to close out NIOSH Technical Assistance at the shelter. However, we understand that the work outlined in the recommendations above will take several months to complete and will represent a significant investment of time and financial resources. As the work proceeds, NIOSH could assist by:

- Reviewing Requests for Proposal developed to initiate the bidding process.

- Reviewing bids received in response to Requests for Proposals for technical content.

- Providing technical assistance related to environmental control strategies, including upper-room UVGI systems. 
It is not necessary for NIOSH to be on-site during ventilation renovations. Yet, as projects are initiated, we can assist you by reviewing:

- Proposed modification strategies for outdoor air introduction or respiratory separation area designs.

- Preliminary design schematics or equipment selection documents.

- Air flow testing and balancing reports.

Once the renovations are complete, if additional NIOSH assistance is desired or warranted, the request for technical assistance can be reopened. 


\section{References}

ACGIH (American Conference of Governmental Industrial Hygienists) [2013]. Threshold limit values for chemical substances and physical agents \& biological exposure indicies. Cincinnati, $\mathrm{OH}$ : American Conference of Governmental Industrial Hygienists.

ANSI/ASHRAE (American National Standards Institute/American Society of Heating, Ventilating and Air-Conditioning Engineers) [2012]. Method of testing general ventilation air-cleaning devices for removal efficiency by particle size. Atlanta, GA: American Society of Heating, Refrigerating and AirConditioning Engineers. Standard 52.2-2012.

ANSI/ASHRAE [2013a]. Ventilation for acceptable indoor air quality. Atlanta, GA: American Society of Heating, Refrigerating and Air-Conditioning Engineers. Standard 62.1-2013.

ANSI/ASHRAE [2013b]. Thermal environmental conditions for human occupancy. Atlanta, GA: American Society of Heating, Refrigerating and Air-Conditioning Engineers. Standard 55-2013.

ASHRAE [2011]. Ultraviolet air and surface treatment. In: ASHRAE Handbook - HVAC Applications, Chapter 60. Atlanta, GA: American Society of Heating, Refrigerating and AirConditioning Engineers.

ASHRAE [2012]. Ultraviolet lamp systems. In: ASHRAE Handbook - HVAC Systems and Equipment, Chapter 17. Atlanta, GA: American Society of Heating, Refrigerating and Air-Conditioning Engineers.

Barry MA, Wall C, Shirley L, Bernardo J, Schwingl P, Brigandi E, Lamb GA [1986]. Tuberculosis screening in Boston's homeless shelters. Public Health Rep 101(5):487-498.

Brickner PW, Vincent RL, First M, Nardell E, Murray M, Kaufman W [2003]. The application of ultraviolet germicidal irradiation to control transmission of airborne disease: bioterrorism countermeasure. Public Health Rep 118:99-118.

CDC (Centers for Disease Control and Prevention) [1985]. Drug-resistant tuberculosis among the homeless-Boston. MMWR 34:429-431.

CDC [1992]. Prevention and control of tuberculosis among homeless persons (ACET). MMWR 41(RR-5):001.

CDC [2003a]. Tuberculosis outbreak in a homeless population-Portland, Maine, 2002-2003. MMWR 52(48):1184-1185.

CDC [2003b]. TB outbreak among homeless persons-King County, Washington, 2002-2003. MMWR 52(49):1209-1210.

CDC [2005a]. Tuberculosis transmission in a homeless shelter population-New York, 2000-2003. MMWR 54(06):149-152.

CDC [2005b]. Guidelines for preventing the transmission of Mycobacterium tuberculosis in healthcare settings, 2005. MMWR 54(RR-17):1-141. 
CDC [2006]. Prevention and control of tuberculosis in correctional and detention facilities:

Recommendations from CDC. MMWR 55(RR-9):1-54.

City of Dallas [2013]. Dallas mechanical code. In: Dallas City Code, Chapter 55. Dallas, TX: City Council of the City of Dallas, Ordinance No. 29163.

David HL [1973]. Response of mycobacteria to ultraviolet light radiation. Am Rev Respir Dis 108:1175-85.

EPA (US Environmental Protection Agency) [2012]. The inside story: A guide to indoor air quality. http://www.epa.gov/iaq/pubs/insidestory.html. Date accessed: February 22, 2013.

FGI (Facility Guidelines Institute) [2010]. Guidelines for design and construction of health care facilities. Chicago, IL: American Society for Healthcare Engineering of the American Hospital Association.

First MW, Nardell EA, Chaisson W, Riley R [1999a]. Guidelines for the application of upper-room ultraviolet germicidal irradiation for preventing transmission of airborne contagion - Part I: basic principles. ASHRAE Trans 105(1):CH-99-12-91.

First MW, Nardell EA, Chaisson W, Riley R [1999b]. Guidelines for the application of upper-room ultraviolet germicidal irradiation for preventing transmission of airborne contagion - Part II: design and operation guidance. ASHRAE Trans 105(1):CH-99-12-92.

ICC (International Code Council, Inc.) [2012]. 2012 international mechanical code. Country Club Hills, IL: International Code Council, Inc.

Knopf SA [1914]. Tuberculosis as a cause and result of poverty. J Am Med Assoc 63(20):1720-1725.

McAdam JM, Brickner PW, Scharer LL, Crocco JA, Duff AE [1990]. The spectrum of tuberculosis in a New York City men's shelter clinic (1982-1988). Chest 97:798-805.

McLean RL [1961]. General discussion: the mechanism of spread of Asian influenza. Am Rev Respir Dis 83:29-40.

NIOSH [1972]. Criteria for a recommended standard: occupational exposures to ultraviolet radiation. By Seiter RE. Cincinnati, OH: U.S. Department of Health, Education, and Welfare, Health Services and Mental Health Administration, National Institute for Occupational Safety and Health, DHEW (NIOSH) Publication No. HSM-73-11009.

NIOSH [2009]. Environmental control for tuberculosis: basic upper-room ultraviolet germicidal irradiation guidelines for healthcare settings. By Whalen J. Cincinnati, OH: U.S. Department of Health and Human Services, Centers for Disease Control and Prevention, National Institute for Occupational Safety and Health, DHHS (NIOSH) Publication No. 2009-105. http://www.cdc.gov/niosh/docs/2009105/pdfs/2009-105.pdf. Date accessed: March 22, 2013.

Nolan CM, Elarth AM, Barr H, Saeed AM, Risser DR [1991]. An outbreak of tuberculosis in a shelter for homeless men: A description of its evolution and control. Am Rev Respir Dis 143:257-261. 
Riley RL, Wells WF, Mills CC, Nyka W, McLean RL [1957]. Air hygiene in tuberculosis: quantitative studies of infectivity and control in a pilot ward. Am Rev Tubercul 75:420-31.

Riley RL, Mills CC, O’Grady F, Sultan LU, Wittstadt F, Shivpuri DN [1962]. Infectiousness of air from a tuberculosis ward. Am Rev Respir Dis 85:511-25.

Riley RL, Knight M, Middlebrook G [1976]. Ultraviolet susceptibility of BCG and virulent tubercle bacilli. Am Rev Respir Dis 113:413-18.

Riley RL, Nardell EA [1989]. Clearing the air: the theory and application of ultraviolet air disinfection. Am Rev Respir Dis 139(5):1286-94.

Slutkin G [1986]. Management of tuberculosis in urban homeless indigents. Public Health Rep 101(5):481-485.

Wells WF, Holla, WA [1950]. Ventilation in the flow of measles and chickenpox through a community: progress report, January 1, 1946 to June 15, 1949-airborne infection study, Westchester County department of health. J Am Med Assoc 142:1337-44.

Willmon TL, Hollaender A, Langmuir AD [1948]. Studies of the control of acute respiratory diseases among naval recruits. I. a review of a four-year experience with ultraviolet irradiation and dust suppressive measures, 1943 to 1947. Am J Hyg 48:227-32.

Xu P, Peccia J, Fabian P, Martyny JW, Fennelly KP, Hernandez M, Miller SL [2003]. Efficacy of ultraviolet germicidal irradiation of upper-room air in inactivating airborne bacterial spores and mycobacteria in full-scale studies. Atmos Environ 37:405-19. 


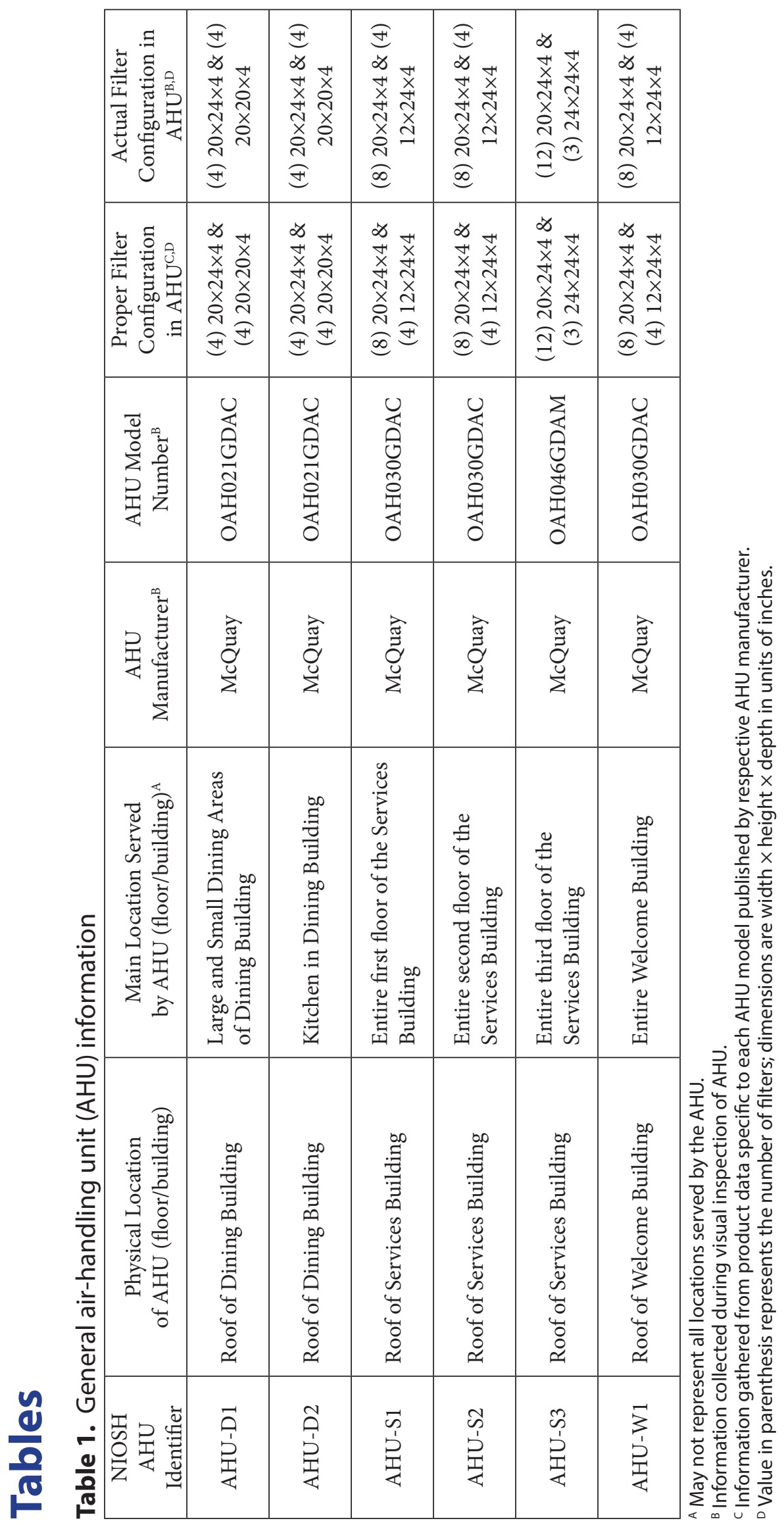




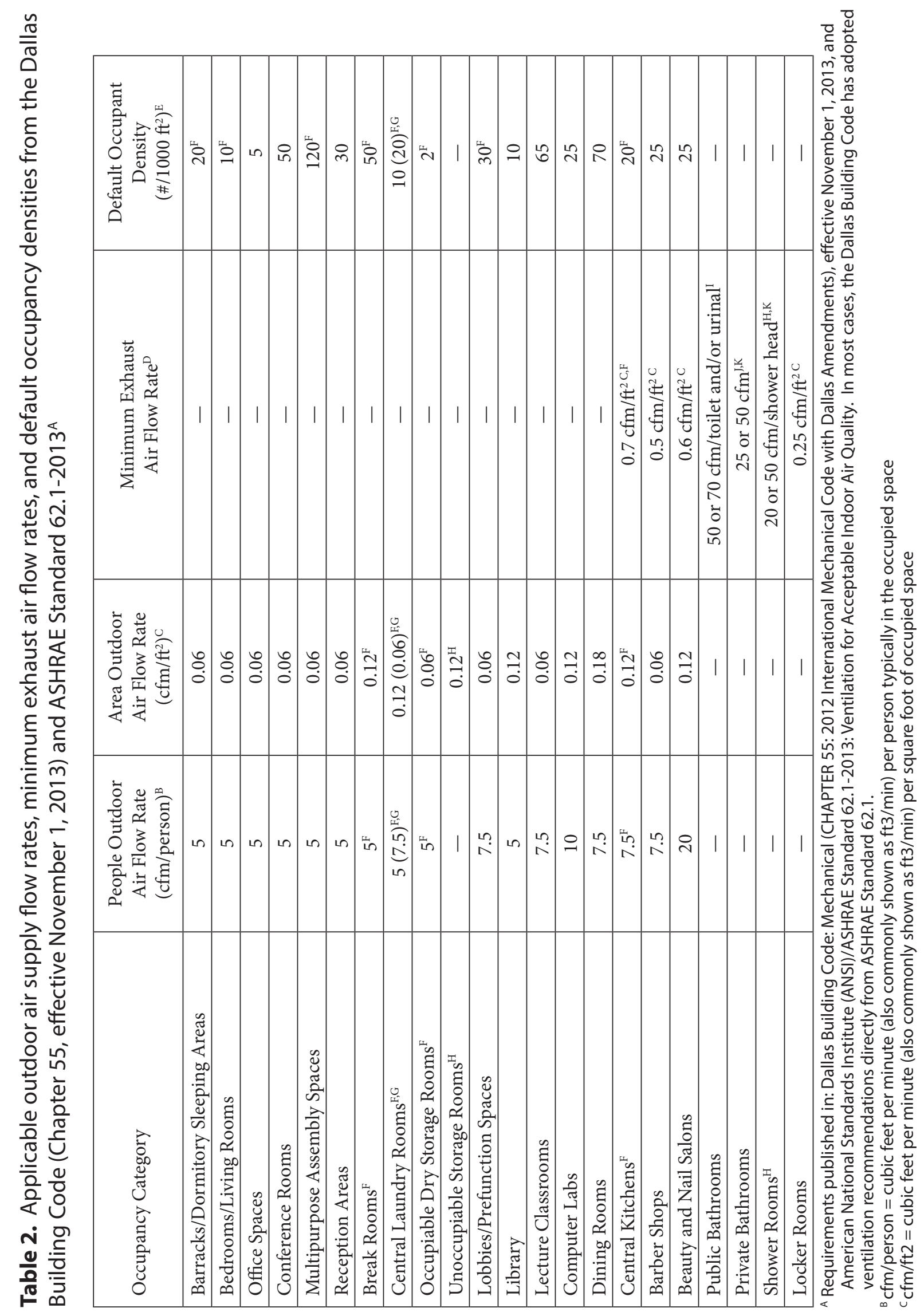




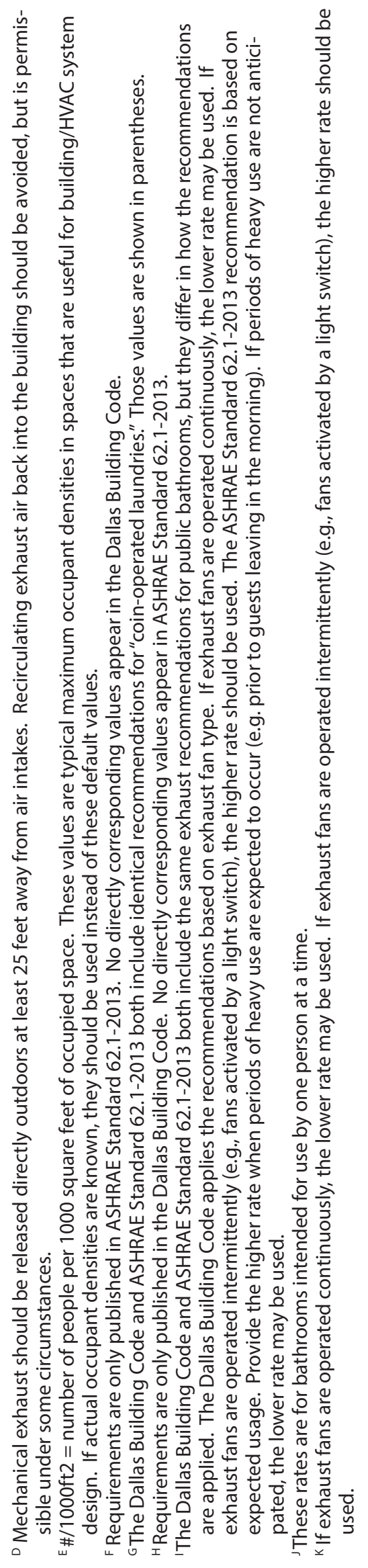




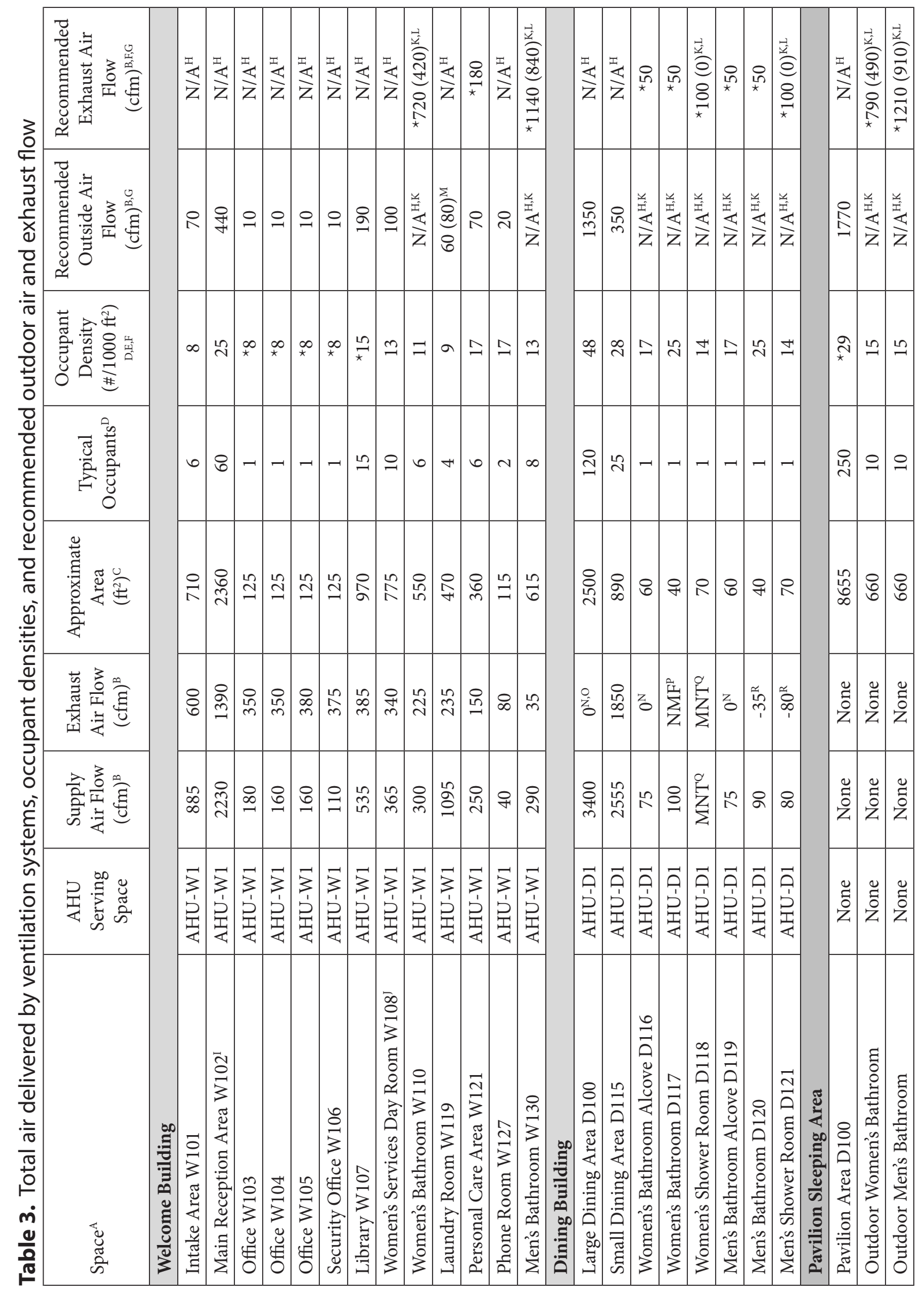




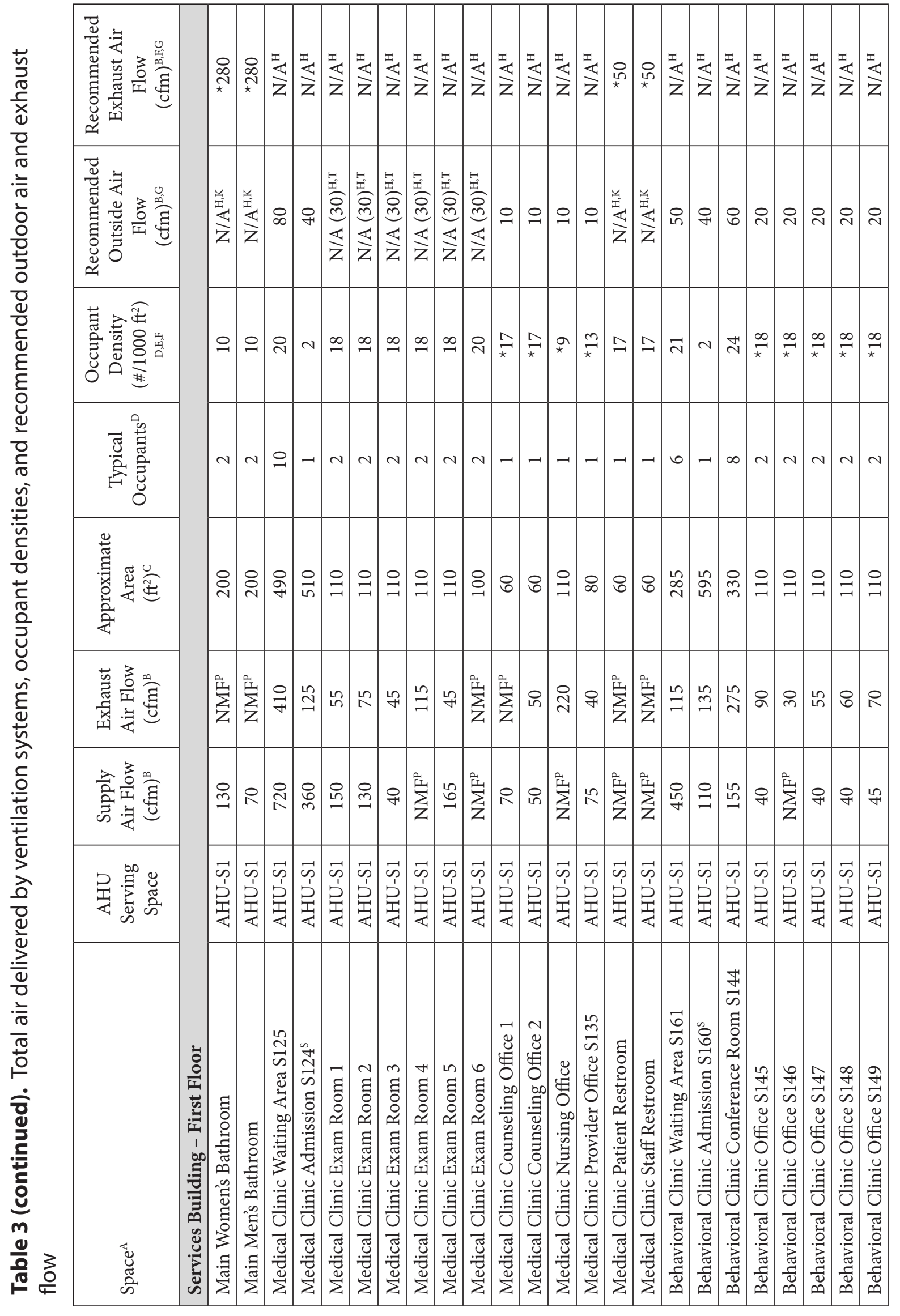




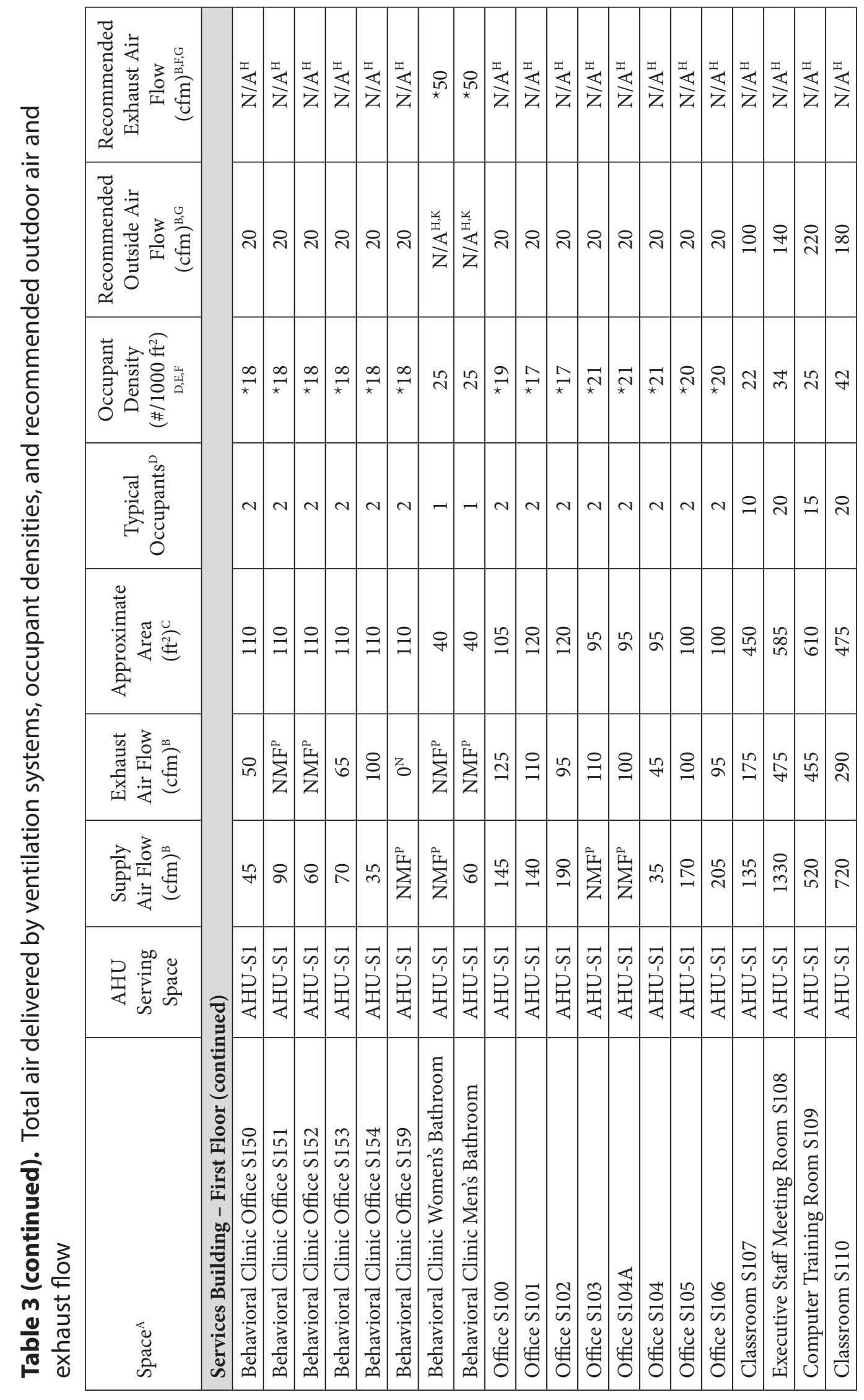




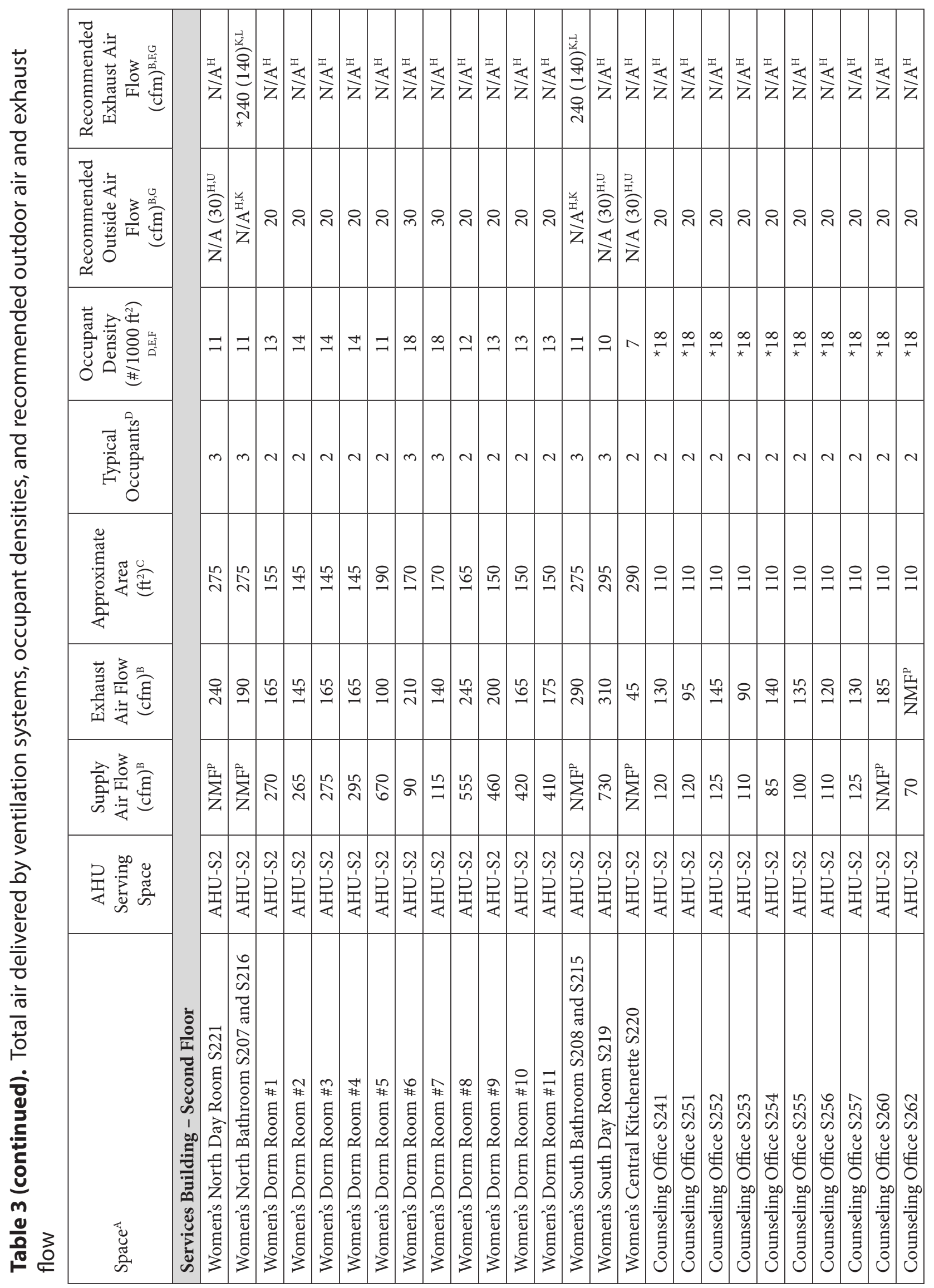




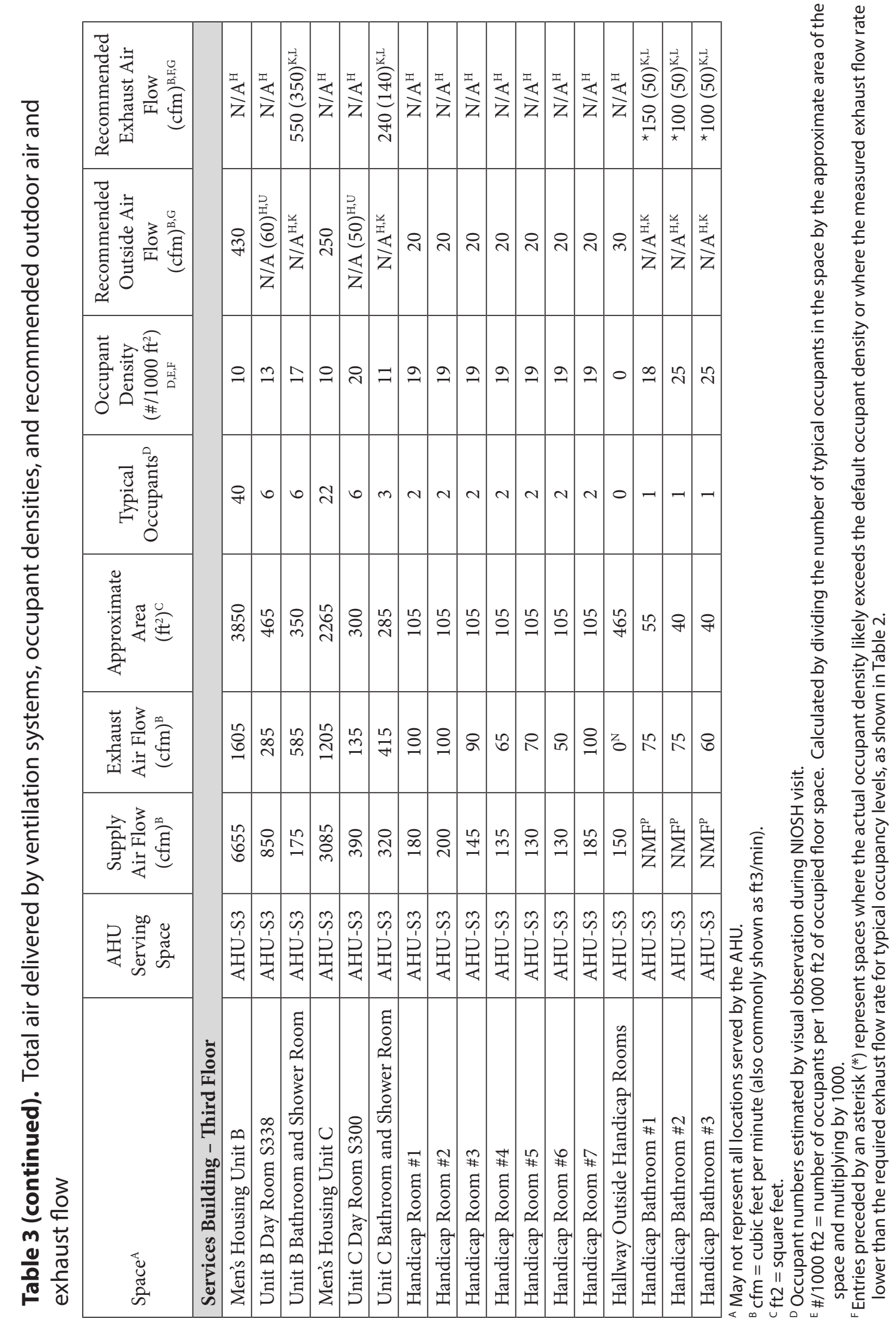




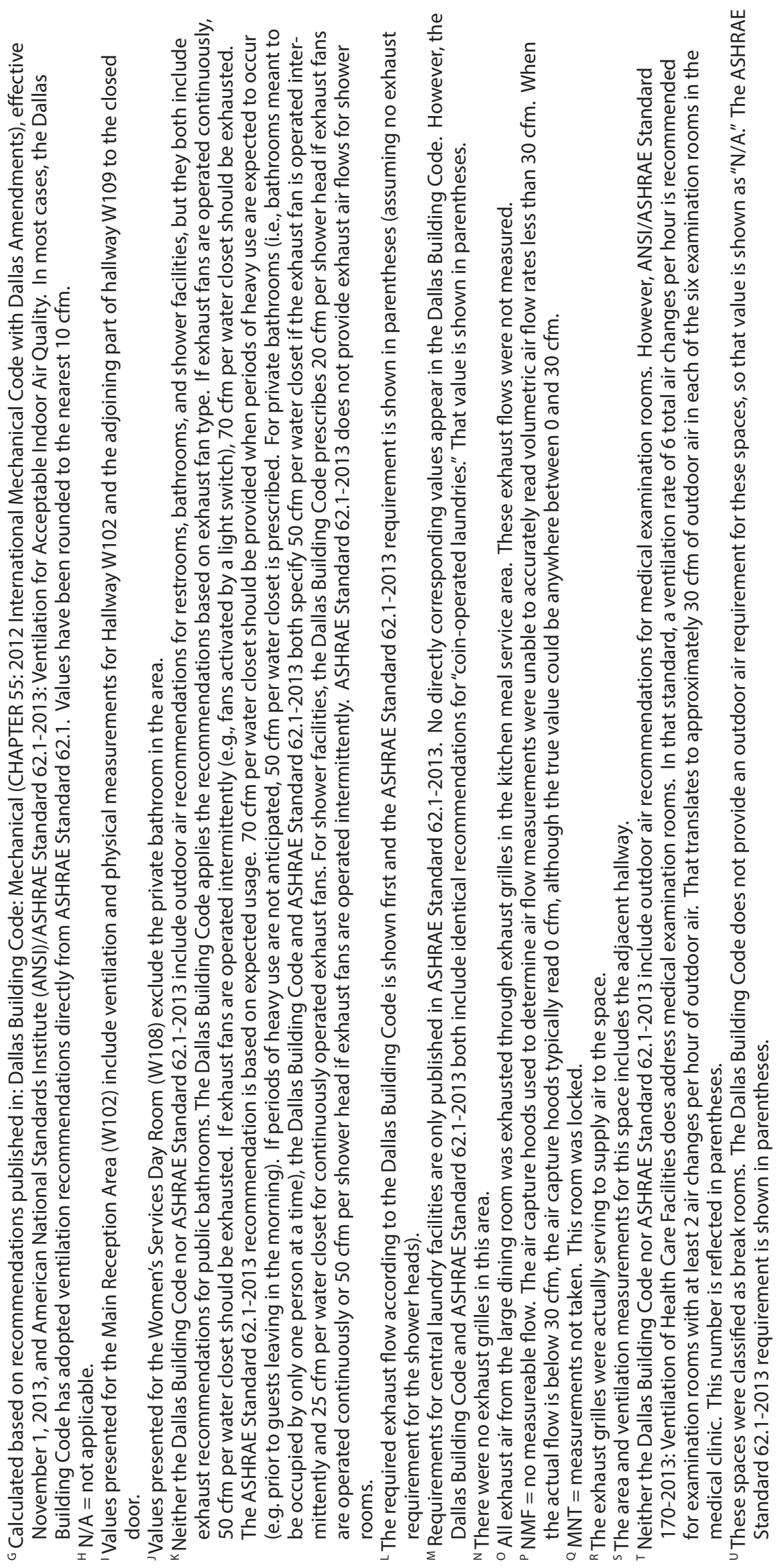




\section{Figures}

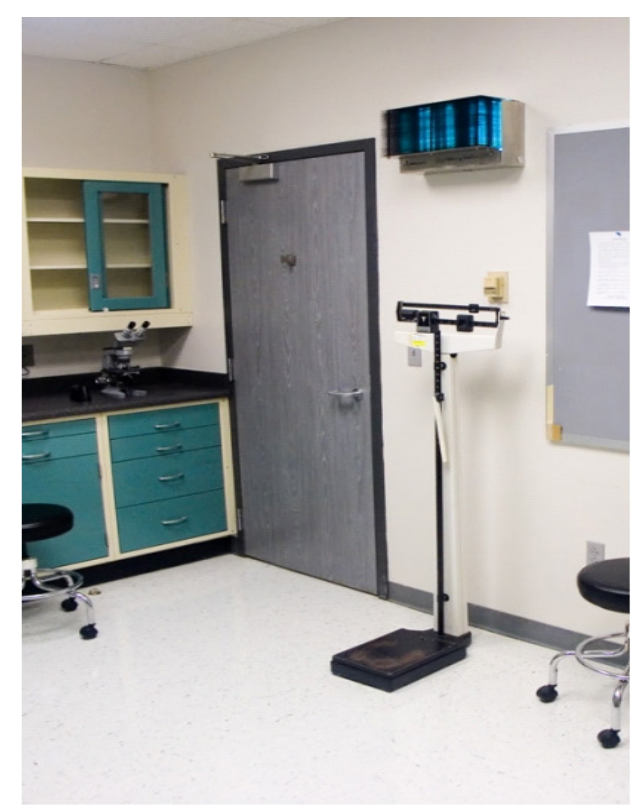

$\mathbf{A}$

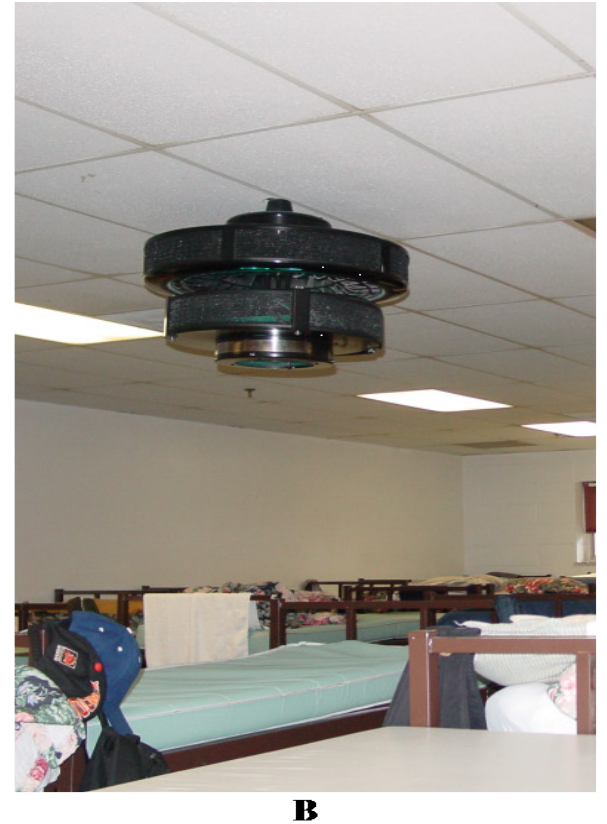

B

Figure 1. Typical upper-air UVGI installations: Left-Wall-mounted fixture with louvers installed in a health clinic; Right-Ceiling-mounted fixture with an internal fan installed in a homeless shelter. 
This page left intentionally blank 
Keywords: NAICS 624221 (Temporary Shelters), tuberculosis, environmental controls, ventilation, homeless shelter, airborne infection, airborne transmission, respiratory 
The Health Hazard Evaluation Program investigates possible health hazards in the workplace under the authority of the Occupational Safety and Health Act of 1970 (29 U.S.C. \$669(a)

(6)). The Health Hazard Evaluation Program also provides, upon request, technical assistance to federal, state, and local agencies to investigate occupational health hazards and to prevent occupational disease or injury. Regulations guiding the Program can be found in Title 42, Code of Federal Regulations, Part 85; Requests for Health Hazard Evaluations (42 CPR Part $85)$.

\section{Disclaimer}

The recommendations in this report are made on the basis of the findings at the workplace evaluated and may not be applicable to other workplaces.

Mention of any company or product in this report does not constitute endorsement by the National Institute for Occupational Safety and Health (NIOSH).

Citations to Web sites external to NIOSH do not constitute NIOSH endorsement of the sponsoring organizations or their programs or products. NIOSH is not responsible for the content of these Web sites. All Web addresses referenced in this document were accessible as of the publication date.

\section{Acknowledgments}

Desktop Publisher: Tia McClelland

\section{Availability of Report}

Copies of this report have been sent to representatives from the shelter, DCHHS, the Texas Department of State Health Services, CDC/NCHHSTP/DTBE, and the OSHA Regional Office. This report is not copyrighted and may be freely reproduced. This report is available at http://www.cdc.gov/niosh/hhe/reports/pdfs/2013-0145-3209.pdf.

\section{Recommended citation for this report:}

$\mathrm{NIOSH}$ [2014]. Health hazard evaluation report: evaluation of environmental controls at a homeless shelter associated with a tuberculosis outbreak - Texas. By Martin, Jr. SB, Lawrence RB, Mead KR. Morgantown, WV: U.S. Department of Health and Human Services, Centers for Disease Control and Prevention, National Institute for Occupational Safety and Health, NIOSH HETA No. 2013-0145-3209. 
Delivering on the Nation's promise:

Safety and health at work for all people through research and prevention

To receive documents or other information about occupational safety and health topics, contact NIOSH

Telephone: 1-800-CDC-INFO (1-800-232-4636)

TTY: 1-888-232-6348

email: cdcinfo@cdc.gov

or visit the NIOSH website at http://www.cdc.gov/niosh

SAFER • HEALTHIER • PEOPLE ${ }^{\text {TM }}$ 